\title{
CAN OPTIMISM ABOUT TECHNOLOGY STOCKS BE GOOD FOR WELFARE? POSITIVE SPILLOVERS VS. EQUITY MARKET LOSSES
}

\author{
Katrin Tinn \\ Evangelia Vourvachaki
}
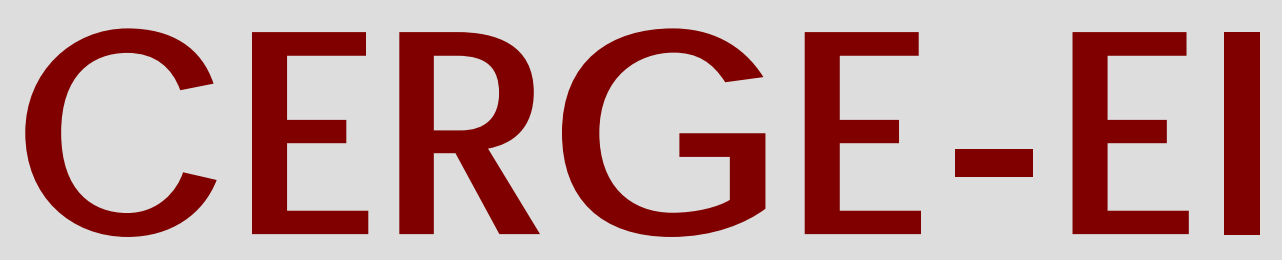

Charles University Centerfor Economic Research and Graduate Education Academy of Sciences of the Czech Republic Ec onomic s Institute 


\title{
Working Paper Series 383 (ISSN 1211-3298)
}

\section{Can Optimism about Technology Stocks Be Good for Welfare? Positive Spillovers vs. Equity Market Losses}

\author{
Katrin Tinn \\ Evangelia Vourvachaki
}

CERGE-EI

Prague, April 2009 
ISBN 978-80-7343-184-6 (Univerzita Karlova. Centrum pro ekonomický výzkum a doktorské studium)

ISBN 978-80-7344-173-9 (Národohospodářský ústav AV ČR, v.v.i.) 


\title{
Can Optimism about Technology Stocks Be Good for Welfare? Positive Spillovers vs. Equity Market Losses*
}

\author{
Katrin $\operatorname{Tinn}^{\dagger}$ \\ Stockholm School of Economics \\ SITE
}

\author{
Evangelia Vourvachaki ${ }^{\ddagger}$ \\ CERGE-EI
}

April 2009

\begin{abstract}
This paper analyzes the impact of equity market information imperfections on $R \& D$ driven growth. The mechanism proposed is built on two premises. First, the R\&D-sector relies largely on equity finance, because of its production features. Second, equity can be persistently mispriced. This is due to investors rationally taking into account both private and public information. This paper shows that optimism in equity market can generate long-run consumption gains, despite the excess capital losses realized in the short-run. This result arises from the externalities in R\&D production that result in uderinvestment in R\&D in a market economy with perfect information.
\end{abstract}

\begin{abstract}
Abstrakt
Tento článek studuje, jak optimismus na akciových trzích může přinést zvýšenou prosperitu na celkové úrovni i přes to, že firmy čelí motivaci v podobě záporné současné hodnotě investic. Když ceny akcií ovlivní investiční rozhodování firem s intenzivním R\&D, optimismus optimálně zvýší ex-ante celkovou hodnotou R\&D investic a produkce. Na jednu stranu spotřebitelé čelí ex-post ztrátě z držby akcií, na druhou stranu získají v podobě vyšších platů. Zisk je způsoben vyšší produktivitou kvůli pokročilejším technologiím. Celkový pozitivní nárůst prosperity je možný proto, že soukromé zisky z R\&D jsou nižší než zisky z pohledu společnosti. Optimismus na akciových trzích může vytvořit Pareto vylepšení, pokud produktivita v R\&D je vysoká a optimismus dlouhotrvající.
\end{abstract}

JEL classification: $\mathrm{G} 12, \mathrm{O} 30, \mathrm{O} 40$

Keywords: Equity mispricing, R\&D growth, Optimism, Welfare

\footnotetext{
* The authors would like to thank Francesco Caselli, Byeongju Jeong, Nobuhiro Kiyotaki, Rachel Ngai, Christopher Pissarides, Stefano Rossi, Jonathan Temple, Danny Quah for helpful comments and Sarah Peck for english editing.

${ }^{\dagger}$ Contact details: Katrin Tinn, Stockholm School of Economics, Box 6501, SE-113 83, Stockholm, Sweden, katrin.tinn@hhs.se

$\$$

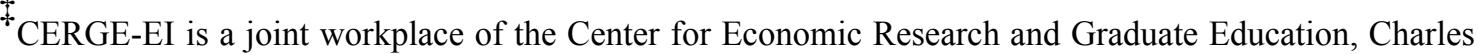
University, and the Economics Institute of the Academy of Sciences of the Czech Republic. Evangelia Vourvachaki, evangelia.vourvachaki@cerge-ei.cz.
} 


\section{Introduction}

If anything is to characterize the late 1990s in the United States, it is the drastic development of new technologies and temporary increase of the equity prices of the firms producing them. This period of high optimism in the pricing of technology stocks was accompanied by high output and wage growth. ${ }^{1}$ Similar booms and busts of stock prices are documented in earlier episodes of intense technological change (e.g., railroads, electricity, biotechnologies; see Shiller 2000). Such episodes are dramatic demonstrations of the underlying long-run positive correlation between equity prices and R\&D output. Figure 1 shows the relationship between a measure of equity overpricing (the real price earnings ratio) of the firms listed in S\&P500, and the number of patents granted by USPTO to United States non-government institutions. $^{2}$ The boom in the late 1990s episode stands out from the graph. ${ }^{3}$

These facts have triggered a vivid public discussion about the effect of optimism in the equity market for the aggregate economy. This discussion focuses on an important trade-off that is summarized in the words of Thomas L. Friedman of the New York Times: "..in the 20th century, we all know, we had this dot-coms boombubble-and-bust. Most people, at the end, lost money on dot-coms, but it left us with this incredible internet highway, on which Google and Microsoft emerged and forged whole new industries" (MSNBC, October 22, 2008). ${ }^{4}$

The general equilibrium model developed in this paper accounts explicitly for such trade-off between equity market losses and productivity gains from the faster development of new technologies. The main question of this paper is whether over-

\footnotetext{
${ }^{1}$ The United States' average annual labour productivity growth accelerated by $1.05 \mathrm{pp}$. in the mid-1990s (Table 8.3 in Jorgenson, Ho, and Stiroh 2005). Real earnings for the median worker also grew sharply. Wage gains during 1989-1999 amounted to 6.9 percent, and employment gains to 15 percent (Ilg and Haugen 2000).

${ }^{2}$ Figure 1 presents the series in log levels and their respective trends (Hodrick-Prescott filter with $\lambda=100$ for annual data). Data on price earnings ratio and patents are from the websites of Robert J. Shiller and Bronwyn H. Hall, respectively. Price earnings is often referred as an indicator of the extent of equity mispricing (e.g., see Jermann and Quadrini 2007).

${ }^{3}$ The Information and Communication Technologies sector was the main actor in the late 1990s' correlation. Carlin and Mayer (2003) show that the ICT-producing sector is highly intensive in R\&D and patenting activity. Jorgenson, Ho, and Stiroh (2005) find that this sector contributes $30 \%$ to the post 1990 s accelation of the United States' TFP growth.

${ }^{4}$ In the same interview a popular analogy is drawn: "..in the 19th century we had a boom-bubbleand-bust... around railroads. Everyone went out and bought railroad stocks. Most people lost money, but it left us with this incredible national railroad system, that knitted our country together..".
} 


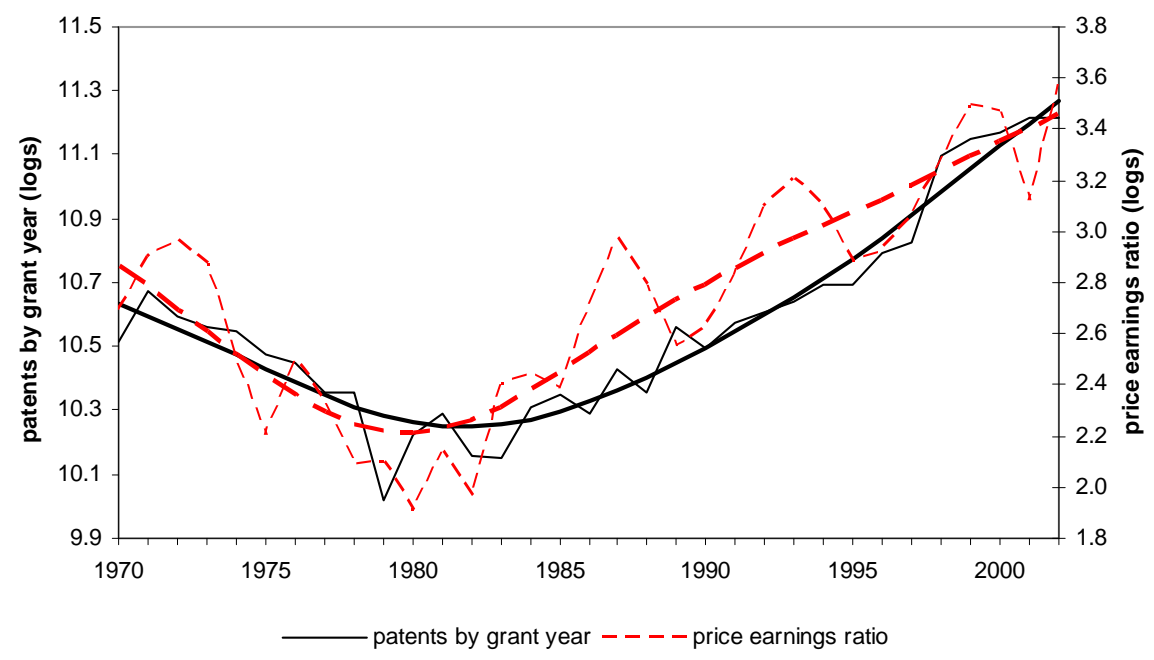

Figure 1: S\&P500 price earning ratio and USPTO patents granted to nongovernment institutions.

pricing of R\&D intensive firms' equity can increase aggregate welfare. The answer to this is found positive, because optimism gives rise to positive spillovers that can compensate for the losses in the equity market.

The intuition for this result is the following. When R\&D producers' investment decisions are affected by equity prices, optimism in the equity market leads to higher aggregate R\&D investment. In the model, this implies faster entry of new firms, an increase of the size of the equity market, and introduction of new products. As a result, the productivity of the sector using the new products increases. This in turn translates to higher wages for workers, and thereby greater consumption and welfare.

Welfare gains exist due to the positive externalities embedded in R\&D production. The limitations of private ownership imply that the market provides insufficient incentives for $R \& D$ investment. As is common in endogenous growth literature (e.g., Romer 1990, Grossman and Helpman 1991), the owners of firms engaging in R\&D and producing new products have a claim on the future flow of profits from selling the product (an equity contract). However, the equity contract is not a claim on the full benefits of introducing a new product to the market, which permanently in- 
creases productivity in other firms that use the product. ${ }^{5}$ Also, the equity contract is not a claim on the profits of future $R \& D$ producers, on whom the firm exerts a knowledge externality. Equity overpricing creates these "missing" incentives for R\&D investment.

The empirical literature supports the existence of important positive spillovers in R\&D investment. Griliches (1992) reviews numerous empirical studies that suggest significant knowledge spillover: the return to others' R\&D activity is twice as high as the return to private $\mathrm{R} \& \mathrm{D}$ investment. The calibration results of Comin and Gertler (2006) for the Unites States' R\&D production function that resembles the one of this model also suggest large positive spillover effects at the aggregate level.

The creation of new technologies in response to changes in market value of equity and the role of externalities in this process are not taken into account in the existing literature that emphasizes the negative effects of equity overpricing in terms of encouraging negative NPV investments at the firm level (e.g., Farhi and Panageas 2007, Polk and Sapienza 2008). By explicitly accounting for the R\&D externalities, this paper shows that aggregate benefits from optimism can be present, despite the fact that $\mathrm{R} \& \mathrm{D}$ intensive firms engage in unprofitable investments.

Technology innovations are taken as exogenous also in the papers that address why bubble-like development of equity prices is particularly likely to arise in technology intensive sectors (e.g., Pastor and Veronesi 2006, Pastor and Veronesi 2008, DeMarzo, Kaniel, and Kremer 2007). ${ }^{6}$ By focusing on what can cause optimism in relation to new technologies' use, these papers provide an important counterpart of the analysis of the current paper, which focuses on the effect of optimism on technologies' creation.

At the same time, the literature of R\&D based growth models typically abstracts from imperfect information in financial markets. ${ }^{7}$ This paper contributes to this

\footnotetext{
${ }^{5}$ New R\&D products can benefit not only the sectors directly using them, but also ones that do not. Vourvachaki (2006) shows this when the technology-using sector produces capital and intermediates for the rest of the economy.

${ }^{6}$ Neither these papers, nor the present paper, give rise to real bubbles as in Tirole (1985), Ventura (2006) and Caballero, Farhi, and Hammour (2006).

${ }^{7}$ An important exception is Evans, Honkapohja, and Romer (1998). They show how investors' imperfect information and learning move the economy across multiple growth equilibria over stable cycles. In contrast to this, there is a unique and stable solution for the transition path over the period of optimism in the current paper. Optimistic beliefs have only a temporary effect on the
} 
by studying the impact of rational equity mispricing on aggregate outcomes and welfare. This is important not only in order to address the motivating question of the paper, but also because deviation of equity prices from fundamentals are arguably widespread. Numerous empirical studies support the existence of equity mispricing ${ }^{8}$ as well as the impact of market sentiment on equity market participants' expectations and stock prices (e.g., Lee, Shleifer, and Thaler 1991, Swaminathan 1991, Menkhoff 1998).

Equity mispricing has an impact on aggregate consumption only when it affects aggregate investment. The paper abstracts from credit constraints and assumes that entrepreneurs' incentives to invest in $\mathrm{R} \& \mathrm{D}$ are directly affected by the equity price of their firm (i.e., the market value), rather than its future profits. ${ }^{9}$ Such channel may be motivated in several ways. One reason is that the $R \& D$ producers have no superior information compared to the equity market participants. Another reason is that entrepreneurs have a short investment horizon. ${ }^{10}$ In the latter case, R\&D producers could have superior information. In Polk and Sapienza (2008), the equity market participants irrationally overprice firms that make particular investments. For short-horizoned entrepreneurs, this gives an incentive to cater to the market sentiment by making these investments. Tinn (2008) shows how such equity overpricing and higher investments can also emerge in a rational setting. She looks at the technology investment decisions by short-horizoned entrepreneurs with superior information. In such a setting, investments become a positive and noisy signal for rational equity market participants. The resulting increase of the expected market value of the firms generates incentives for further investments.

growth rate, while a permanent effect on the level of output.

${ }^{8}$ There is evidence that equity prices react slowly to changes in the variables that proxy the underlying fundamentals (e.g., Cutler, Poterba, and Summers 1991, Jegadeesh and Titman 1993, Chan, Jegadeesh, and Lakonishok 1996).

${ }^{9}$ The results of the paper would not change if R\&D producers would care about both short-term equity price and future profits.

${ }^{10}$ The short-horizon preferences are motivated in several ways. First, executive compensation packages often depend on equity prices (see Murphy 2002). Second, the initial owners of firms that produce $R \& D$ are likely to have a preference towards fast exit. A major source of financing for R\&D intensive start-ups is venture capital (see Kortum and Lerner 2000), which is known to have a preference toward fast exit (e.g. Jovanovic and Szentes 2007). More generally, if agents are heterogeneous in their innovative/ entrepreneurial skills, it is optimal for talented entrepreneurs to specialize in establishing new firms and selling their firms fast in the equity market (Holmes and Schmitz Jr. 1990). 
A positive relationship between equity prices and investment at the aggregate economy, or firm-level has overwhelming empirical support (e.g., Barro 1990, Morck, Shleifer, and Vishny 1990, Blanchard, Rhee, and Summers 1993). Also, Gilchrist, Himmelberg, and Huberman (2005), Farhi and Panageas (2007), and Polk and Sapienza (2008) document a positive relationship between equity overpricing and real investments. Equity overpricing is also positively related to final output productivity, as presented by Jermann and Quadrini (2007), and R\&D output, as depicted in Figure 1. ${ }^{11}$

In addition to increasing incentives to invest in technology, equity overpricing can have a positive effect on investments by reducing the cost of external financing (as in Stein 1996). Such a channel is shown to be empirically relevant by Baker, Stein, and Wurgler (2003). A general equilibrium model that examines the role of equity overpricing in relaxing credit constraints is that of Jermann and Quadrini (2007). The model of this paper is viewed as complementary to the ones focusing on the role of financing costs. It is worth emphasizing that in models with financing constraints only, equity market optimism does not lead to higher than optimal investment at the firm level (i.e., investment can not be higher than the discounted future profits of firms that invest). On the contrary, in the model of this paper, equity overpricing leads to higher R\&D investment, which imply negative NPV at the firm-level. This feature is consistent with the empirical findings of Polk and Sapienza (2008), who find that equity overpricing leads to higher investments, even when controlling for the role of equity issuance in alleviating credit constraints. It is also worth noting that introducing financing constraints for the R\&D firms to the current paper would strengthen the positive aggregate impact of optimism. This is because optimism will alleviate not only market distortions related to limited ownership on the returns from private $\mathrm{R} \& \mathrm{D}$ investments, but also the ones related to not allowing profitable investment projects to be undertaken.

The model introduces temporary optimism about the profits of the R\&D firms, through noisy public signals that are regularly released. Each of these signals re-

\footnotetext{
${ }^{11}$ This evidence cannot be explained within the efficient equity markets hypothesis, where there is no room for changes in the equity prices to cause changes in $R \& D$ investment and patenting activity (e.g., Pakes (1985) and Griliches, Hall, and Pakes (1991)).
} 
mains informative for a limited period of time and affects all rational investors beliefs in the same direction. The benefits and costs from positive errors in public information are examined through an overlapping generations framework, which highlights the effect of optimism on consumers' income throughout the boom and bust episode. The welfare analysis treats all generations equally. The criterion for welfare gains is conservative, since it requires Pareto improvement for each generation of consumers compared to the economy, where there is perfect information in the equity market.

By assuming away irrational mispricing, consumption smoothing and inter-generational consumption trade-offs, the result for potential welfare gains is more striking. The presence of welfare gains is more likely the higher is the productivity of the R\&D investment. Welfare gains are also more likely the more credible and persistent is the public information in investors' beliefs and the lower the degree of optimism it injects.

The baseline model assumes that consumers have only public information. In its extension, the paper introduces heterogeneous and noisy private information. The main findings are shown to remain robust, since the public signal retains a persistent effect on equity prices (as in Allen, Morris, and Shin (2006) and Bacchetta and Wincoop (2007)). This extension introduces higher order expectations and learning from equity prices. Both of these forces imply that the losses from equity market optimism are distributed across more generations of consumers. In this case, guaranteeing higher consumption of all generations requires consecutive releases of optimistic public signals.

As a final note, the assumptions in this paper do not prevent the mispricing of equity to go in either direction from the fundamentals, ${ }^{12}$ i.e., the public signals that drive equity mispricing are equally likely to be optimistic or pessimistic. As discussed above, optimism could be introduced by allowing R\&D investment itself to work as a positive public signal to equity market participants. Furthermore, the presence of welfare gains from equity market optimism can create incentives for policy makers to influence the public signal towards optimism.

The paper is organized as follows. Section 2 presents the basic model where

\footnotetext{
${ }^{12}$ Pessimism would result in equity underpricing with the reverse effects on aggregate outcomes.
} 
consumers have only public information. Section 3 presents the results and focuses on the impact of temporary optimism on consumption. Section 4 extends the analysis to consider consumers that have heterogeneous private information. Section 5 summarizes the implications of the model and discusses the role of policy.

\section{The Model}

\subsection{Consumers}

The economy is populated with overlapping generations of consumers, who work and invest in assets in the first period of their lives, and consume and retire in the second period of their lives. Each generation consists of a continuum of consumers normalized in interval $[0,1]$.

Each consumer born in period $t$ is endowed with $L$ units of labor that he supplies to the final goods producing sector for a wage $w_{t}$. The assets available are risk-free bond and equity. The risk-free bond offers a gross return $R>1$ and its supply is infinitely elastic. ${ }^{13}$ The supply of equity in period $t$ is $S_{t}$ and involves shares of monopolistic firms that engage in $\mathrm{R} \& \mathrm{D}$ investment and intermediate goods production. All firms pay out their profits as dividends, $\pi_{t}$, and their shares are traded in the equity market at the post-dividend price $P_{t}$. The symmetry across assets is a conjecture to be verified in equilibrium and is due to the lack of firm-specific risks.

The budget constraint of a consumer $i$ born in period $t$ is

$$
\begin{aligned}
w_{t} L & =m_{t}(i)+P_{t}\left[h_{t}(i)+S_{t}\right], \\
c_{t+1}(i) & =\left(P_{t+1}+\pi_{t+1}\right)\left[h_{t}(i)+S_{t}\right]+R m_{t}(i),
\end{aligned}
$$

where $c_{t+1}(i)$ is his consumption in period $t+1, m_{t}(i)$ is his investment in riskfree bond and $S_{t}+h_{t}(i)$ is his investment in equity. The presence of $S_{t}$ in the demand for equity guarantees that consumers hold all the equity available in the

\footnotetext{
${ }^{13}$ The paper abstracts from the endogeneous determination of the interest rate in order to focus on the immediate effects of equity mispricing on consumption without considering consumers' intertemporal allocation of consumption. The interest rate $R$ can be interpreted as the world interest rate in a small open economy setting, or as a return from another industry within the country.
} 
market. However, each of them can adjust their equity demand by choosing $h_{t}(i)$ (i.e., "excess" equity demand).

Consumers face no short-sales or borrowing constraints. They have mean-variance utility and choose $m_{t}(i)$ and $h_{t}(i)$ to maximize

$$
\max _{m_{t}(i), h_{t}(i)}\left\{E\left[c_{t+1}(i) \mid \Omega_{t}(i)\right]-\frac{\gamma}{2} \operatorname{Var}\left[c_{t+1}(i) \mid \Omega_{t}(i)\right] \text {, s.t. }(1)\right\}
$$

where $\Omega_{t}(i)$ is the information set available to consumer $i$ in period $t$. In the basic setup presented in Section 2.4, all consumers have identical information, i.e., $\Omega_{t}(i)=\Omega_{t}$ for every $i$. This assumption is relaxed in Section 4 that considers consumers with heterogeneous information.

\subsection{Final good production}

Competitive final good producers use labour, $L$, and all available intermediate goods to produce output $Y_{t}$. There is a continuum of distinct intermediate good varieties available in period $t$, denoted with $x_{t}(j)$, where $j \in\left[0, A_{t}\right]$ and $A_{1}>0$. The production function is

$$
Y_{t}=\left(\phi_{t} L\right)^{1-\alpha} \int_{0}^{A_{t}} x_{t}^{\alpha}(j) d j ; \alpha \in(0,1)
$$

where $\phi_{t}$ is the labour augmenting productivity shock. The productivity shock is drawn at the beginning of every period $t$ from a publicly known distribution, $\phi_{t} \sim N\left(\bar{\phi}, 1 / \beta_{\phi}\right){ }^{14}$

The price of the final good is normalized to one. Final goods producers take the wage, $w_{t}$, and the price of intermediate goods, $p_{x_{t}}(j)$, as given and maximize profits:

$$
\max _{L,\left\{x_{t}(j)\right\}_{j}}\left\{Y_{t}-\int_{0}^{A_{t}} p_{x_{t}}(j) x_{t}(j) d j-w_{t} L \text { s.t. }(3)\right\} .
$$

The intermediate-goods depreciate fully within a period.

\footnotetext{
${ }^{14}$ The normality assumption is used to simplify the solution of the model. The main mechanism would remain valid with different distributional assumptions. Despite allowing for the possibility of a negative outcome, it is an assumption that is used widely in the finance literature about the liquidation value of assets. For reasonable assumptions about the parameters of the distribution, the probability of negative output and asset prices is negligible.
} 


\subsection{Intermediate good and $\mathrm{R} \& \mathrm{D}$ production}

The final good producers buy each intermediate good, $x_{t}(j)$, from a monopolistic intermediate goods producing firm $j$.

The production of every unit of intermediate good requires the investment of $\eta$ units of final good. In each period $t$, an intermediate goods producer $j$ maximizes profits $\pi_{t}(j)$

$$
\pi_{t}(j)=\max _{p_{x_{t}}(j), x_{t}(j)}\left\{p_{x_{t}}(j) x_{t}(j)-\eta x_{t}(j), \text { s.t. } p_{x_{t}}(j)=\frac{\partial Y_{t}}{\partial x_{t}(j)}\right\} .
$$

In period $t$, there is a continuum of active intermediate goods producers indexed with $j \in\left[0, A_{t}\right]$.

An intermediates good firm is established by the development of a new variety. The development of a new variety in period $t, e \in\left(A_{t}, A_{t+1}\right]$, requires $\mathrm{R} \& \mathrm{D}$ investment one period before the new variety becomes available, i.e., period $t+1$. This provides the intermediate goods firm, $e$, with infinitely lasting monopolistic power (e.g., by the means of a patent) and its profits are $\pi_{t+k}(e)$, where $k \geq 1$.

The $R \& D$ production sector is fully competitive. $R \& D$ producers take the value of their firm, $P_{t}$, and aggregate productivity of $\mathrm{R} \& \mathrm{D}, \bar{\lambda}_{t}$, as given and maximize their expected net gain from R\&D investment, $I_{t}$,

$$
\max _{I_{t}}\left\{P_{t}\left(A_{t+1}-A_{t}\right)-I_{t} \text {, s.t. } A_{t+1}-A_{t}=\bar{\lambda}_{t} I_{t}\right\} .
$$

It is assumed that the value of a new intermediate good firm is equal to its equity market value. ${ }^{15}$ All intermediate good firms already established in period $t$, i.e., those established before and already producing, $j \in\left[0, A_{t}\right]$, and those currently conducting $\mathrm{R} \& \mathrm{D}, e \in\left(A_{t}, A_{t+1}\right]$, are listed in the equity market. Each of these firms corresponds to one divisible share that is held by the consumers (see (1)). The value of all shares listed in period $t$ is the same, which is a conjecture that is verified from the equilibrium results of Section 3.1.

\footnotetext{
${ }^{15}$ See discussion in the introduction regarding this assumption.
} 


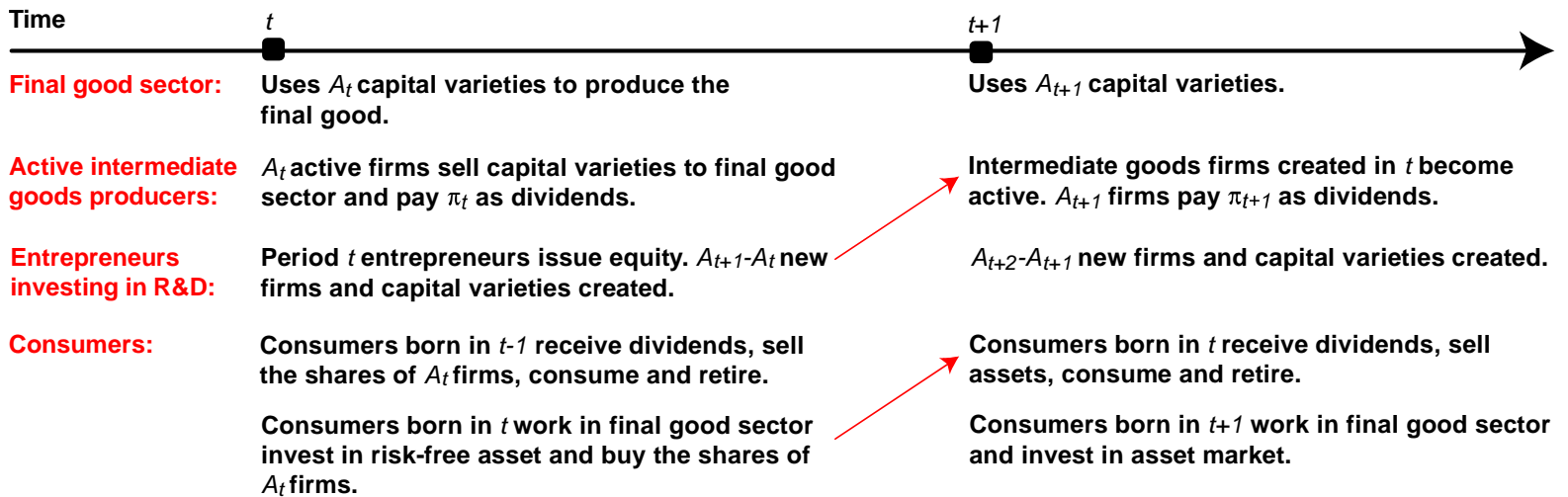

Figure 2: Timing of production and consumption decisions.

While each individual $\mathrm{R} \& \mathrm{D}$ producer takes the $\mathrm{R} \& \mathrm{D}$ productivity $\bar{\lambda}_{t}$ as given, it is a function of aggregate decisions. In the spirit of Comin and Gertler (2006) and Jones (1995),

$$
\bar{\lambda}_{t}=\lambda I_{t}^{\rho-1} A_{t}^{1-\rho} ; \lambda>0, \rho \in\left[\alpha^{\frac{1}{1-\alpha}}, 1\right)
$$

which ensures a well-defined steady-state, bears an exogenous component, $\lambda$, and captures two spillover effects of the individual R\&D entrepreneurs' decisions. First, an increase in the number of known varieties, $A_{t}$, increases permanently the $\mathrm{R} \& \mathrm{D}$ productivity (positive knowledge externality). Second, as the aggregate R\&D investment increases, the marginal productivity of individual R\&D investment decreases (negative congestion externality). The parameter $\rho$ captures the extent of spillover effects (e.g., higher value for $\rho$ implies lower congestion and knowledge externalities). ${ }^{16}$

Figure 2 summarizes the interaction among all agents in this economy and the timing of their actions.

\footnotetext{
${ }^{16}$ The assumption that $\rho \geq \alpha^{\frac{1}{1-\alpha}}$ ensures that aggregate investment in R\&D in the decentralized equilibium is lower than the one corresponding to the first best allocations in the long-run. See discussion in Section 3.2.2 and Appendix D. This assumption is also empirically reasonable, given the calibration of Comin and Gertler (2006) that indicates $\rho \approx 0.8$, while the usual capital share $\alpha \approx 0.3$ gives $\alpha^{\frac{1}{1-\alpha}} \approx 0.179$.
} 


\subsection{Information structure}

Uncertainty about the future labour productivity $\phi_{t}$ implies uncertainty about the demand and thereby profits (dividends) of intermediate goods producers (see Section 3.1.1 below). In the baseline model all the information that consumers have about $\phi_{t}$ is assumed to be public, i.e., all consumers have the same information $\Omega_{t}(i)=\Omega_{t}$. This assumption is relaxed in Section 4. There are two sources of public information.

First, consumers know the prior distribution of the productivity shock $N\left(\bar{\phi}, 1 / \beta_{\phi}\right)$. This gives a "public signal", $\bar{\phi}$, where the productivity innovation itself is the error in this signal. This signal can also be viewed as the average long-run productivity.

Second, all rational consumers trading in period $t$ receive a public signal regarding actual productivity $T$ periods ahead, $\widetilde{\phi}_{t}=\phi_{t+T}+\varepsilon_{\widetilde{\phi}, t}$, where $\varepsilon_{\widetilde{\phi}, t} \sim N\left(0,1 / \beta_{\widetilde{\phi}}\right)$. These signals are introduced to analyze the effect of temporary optimism, which is the central question in this paper. Historical public signals are also public knowledge and thus the information set relevant in period $t$ is

$$
\Omega_{t}=\left\{\bar{\phi}, \widetilde{\phi}_{t}, \ldots, \widetilde{\phi}_{t-T+1}\right\}
$$

\subsection{Markets}

In every period $t$, the final good production, $Y_{t}$, and the returns from the previous period's risk-free asset investment, $R M_{t-1}$, are used to finance aggregate expenditures on consumption, $C_{t} \equiv \int_{0}^{1} c_{t}(i) d i$, investment in intermediate goods production, $X_{t}=\int_{0}^{A_{t}} \eta x_{t}(j) d j, \mathrm{R} \& \mathrm{D}$ investment, $I_{t}$, and purchases of the risk-free asset $M_{t} \equiv \int_{0}^{1} m_{t}(i) d i$. The goods market clearing condition is

$$
R M_{t-1}+Y_{t}=C_{t}+X_{t}+I_{t}+M_{t}
$$

All consumers are employed by the final goods sector $L=\int_{0}^{1} L d i$, and the labour market clears for the equilibrium wage $w_{t}$.

The supply of equity in period $t$ consists of $A_{t}$ shares of current intermediate goods producers and $A_{t+1}-A_{t}$ new shares issued by R\&D producers. The total supply of equity is $S_{t}=A_{t+1}$. The total demand for equity is $H_{t}+S_{t}$, where 
$H_{t} \equiv \int_{0}^{1} h_{t}(i) d i$. The equity market clearing condition is

$$
H_{t}=0
$$

which determines the equilibrium equity price $P_{t}$ that ensures there is no excess demand of equity.

\section{Results}

\subsection{Equilibrium outcomes}

\subsubsection{Final and intermediate good production}

From (3) and (4), the final good producers' optimal demand for variety $j$ is independent of the demand for any other variety $j^{\prime} \neq j$, i.e., $p_{x_{t}}(j)=\alpha L^{1-\alpha} x_{t}^{\alpha-1}(j)$ for any $j$. Using this in (5), the demand for intermediate goods is linear in labor productivity and is the same across intermediate goods producers,

$$
x_{t}(j)=x_{t} \equiv\left(\frac{\alpha^{2}}{\eta}\right)^{\frac{1}{1-\alpha}} L \phi_{t} .
$$

The price of each variety is $p_{x_{t}}(j)=\frac{\eta}{\alpha}$. From (5), this implies that all intermediate goods producers have the same profits,

$$
\pi_{t}=\Gamma \phi_{t} ; \Gamma \equiv \alpha(1-\alpha)\left(\frac{\alpha^{2}}{\eta}\right)^{\frac{\alpha}{1-\alpha}} L
$$

This shows that uncertainty about future labor productivity implies uncertainty about the future profits of intermediate goods producers. Because profits are perfectly correlated across intermediate goods producers, then the equity price, $P_{t}$, needs to be the same across firms in any period $t$. The latter confirms the original conjecture for symmetry of equity prices across firms in Sections 2.1 and 2.3. 


\subsubsection{R\&D production}

An individual R\&D producer's decision for R\&D investment (see equation (6)) determines the relationship between the equity price (the value of a new variety) and individual R\&D productivity, $P_{t}=\frac{1}{\bar{\lambda}_{t}}$. Using (7), the endogeneity of $\bar{\lambda}_{t}$ implies

$$
I_{t}=A_{t} \lambda^{\frac{1}{1-\rho}} P_{t}^{\frac{1}{1-\rho}}
$$

Perfect competition and free entry to R\&D production implies zero profits for R\&D producers and from (6),

$$
P_{t}\left(A_{t+1}-A_{t}\right)=I_{t}
$$

This condition shows that aggregate $R \& D$ investment in period $t$ equals the total stock market value of the new firms producing intermediate goods that are established in the same period.

Using (13) and (14), the R\&D growth rate is an increasing function of equity price, ${ }^{17}$ i.e.,

$$
g_{A, t} \equiv \frac{A_{t+1}-A_{t}}{A_{t}}=\lambda^{\frac{1}{1-\rho}} P_{t}^{\frac{\rho}{1-\rho}}
$$

This highlights that the equilibrium equity price determines the development of $\mathrm{R} \& \mathrm{D}$ over time and therefore real economic activity.

\subsubsection{Asset market equilibrium}

From consumer $i$ 's utility maximization (2), his optimal excess demand for equity in period $t$ is

$$
h_{t}(i)=\frac{E\left[P_{t+1}+\pi_{t+1} \mid \Omega_{t}\right]-R P_{t}}{\gamma \operatorname{Var}\left[P_{t+1}+\pi_{t+1} \mid \Omega_{t}\right]} .
$$

Given that all consumers have identical information, they have the same excess demand. Aggregating excess demand across investors $H_{t}=\int_{0}^{1} h_{t}(i) d i=\frac{E\left[P_{t+1}+\pi_{t+1} \mid \Omega_{t}\right]-R P_{t}}{\gamma \operatorname{Var}\left[P_{t+1}+\pi_{t+1} \mid \Omega_{t}\right]}$ and using the equity market clearing condition (10), the equilibrium equity price

\footnotetext{
${ }^{17}$ See that $\frac{\partial g_{A, t}}{\partial P_{t}}=\lambda^{\frac{1}{1-\rho}} \frac{\rho}{1-\rho} P_{t}^{\frac{\rho}{1-\rho}-1}>0$.
} 
equals

$$
P_{t}=\frac{E\left[P_{t+1}+\pi_{t+1} \mid \Omega_{t}\right]}{R}
$$

Iterating (16) by using the law of iterated expectations and that $E\left[P_{t+1}+\pi_{t+1} \mid \Omega_{t}\right]$ is the same across all consumers, it follows that the equilibrium equity price equals the present discounted value of the expectations of future profits, i.e., $P_{t}=\sum_{k=1}^{\infty} \frac{E\left[\pi_{t+k} \mid \Omega_{t}\right]}{R^{k}}$.

Given (12) and (8) the expected profit flows are $E\left[\pi_{t+k} \mid \Omega_{t}\right]=\Gamma \frac{\beta_{\widetilde{\phi} \widetilde{\phi}_{t-T+k}+\beta_{\phi} \bar{\phi}}}{\beta_{\tilde{\phi}+\beta_{\phi}}}$ if $k \in\{1, . ., T\}$ and $E\left[\pi_{t+k} \mid \Omega_{t}\right]=\Gamma \bar{\phi}$ if $k>T .^{18}$ Therefore, the equilibrium equity price is

$$
P_{t}=z \sum_{k=1}^{T} \frac{1}{R^{k}} \Gamma \tilde{\phi}_{t-T+k}+(1-z) \frac{R^{T}-1}{R^{T}(R-1)} \Gamma \bar{\phi}+\frac{1}{R^{T}(R-1)} \Gamma \bar{\phi},
$$

where $z \equiv \frac{\beta_{\widetilde{\phi}}}{\beta_{\tilde{\phi}+\beta_{\phi}}}$. It is a function of the history of the $T$ public signals that are informative about future productivity and corresponds to the expectation of the present discounted value of profits.

In order to account for the effect of equity market imperfections, a useful benchmark is an economy where consumers have perfect public information; referred as the "PI economy" from now onwards. The PI equilibrium equity price, $P_{t}^{P I}$, equals the actual present discounted value of the future stream of profits, i.e.,

$$
P_{t}^{P I} \equiv \lim _{\beta_{\tilde{\phi}}, T \rightarrow \infty} P_{t}=\sum_{k=1}^{T} \frac{1}{R^{k}} \Gamma \phi_{t+k}
$$

Any wedge between the model's and the PI economy's equity price is due to errors in the public information. ${ }^{19}$

Finally, aggregating consumers' first period budget constraints (1), and using $S_{t}=A_{t+1}$ and (10), the aggregate risk free asset holding is

$$
M_{t}=\int_{0}^{1} m_{t}(i) d i=w_{t} L-P_{t} A_{t+1}
$$

\footnotetext{
${ }^{18}$ Given the public signals, $\bar{\phi}=\phi_{t}-\varepsilon_{\phi_{t}}$, where $\varepsilon_{\phi_{t}} \sim N\left(0,1 / \beta_{\phi}\right)$ and $\widetilde{\phi}_{t-T+k}=\phi_{t+k}+\varepsilon_{\widetilde{\phi}, t-T+k}$, where $\varepsilon_{\widetilde{\phi}, t-T+k} \sim N\left(0,1 / \beta_{\widetilde{\phi}}\right)$, then the posterior distribution of productivity is $\phi_{t+k} \mid \bar{\phi}, \widetilde{\phi}_{t-T+k} \sim$ $N\left(\frac{\beta_{\widetilde{\phi}} \widetilde{\phi}_{t-T+k}+\beta_{\phi} \bar{\phi}}{\beta_{\tilde{\phi}}+\beta_{\phi}}, \frac{1}{\beta_{\tilde{\phi}+\beta_{\phi}}}\right)$. All signals $\widetilde{\phi}_{t-T+l}$ with $l \neq k$ are not informative about $\phi_{t+k}$, and only information about the productivity after the period $t+T$ is its prior distribution.

${ }^{19}$ In particular, $P_{t}-P_{t}^{P I}=\Gamma z \sum_{k=1}^{T} \frac{1}{R^{T-k+1}} \varepsilon_{\tilde{\phi}, T-k+1}-\Gamma(1-z) \sum_{k=1}^{T} \frac{1}{R^{k}} \varepsilon_{k}-\Gamma \sum_{k=T+1}^{\infty} \frac{1}{R^{k}} \varepsilon_{k}$.
} 


\subsubsection{Aggregate consumption, output and goods market clearing}

Using (11) in final goods production function (3), the equilibrium final good production is linear in $\phi_{t}$, given the endogenous productivity level $A_{t}$, i.e.,

$$
Y_{t}=\frac{\Gamma}{\alpha(1-\alpha)} \phi_{t} A_{t}
$$

where $\Gamma$ is defined in (12).

The equilibrium wage is determined by solving the final goods' producers profit maximization problem and is also linear in $\phi_{t}$ given $A_{t}$, i.e., from (4) and (20) $w_{t}=(1-\alpha) \frac{Y_{t}}{L}=\frac{\Gamma}{\alpha L} \phi_{t} A_{t}$.

Aggregate consumption is obtained by aggregating consumers' budget constraint (1). In turn, using the equity market equilibrium condition (10), $S_{t}=A_{t+1}$, (19) and (20),

$C_{t}=\int_{0}^{1} c_{t}(i) d i=\left(P_{t}+\pi_{t}-R P_{t-1}\right) A_{t}+R w_{t-1} L=\left(P_{t}+\pi_{t}-R P_{t-1}\right) A_{t}+R \frac{\Gamma}{\alpha} \phi_{t} A_{t-1}$.

This highlights the channels through which equity market imperfections impact welfare. There is a direct channel from the excess capital gains, $P_{t}+\pi_{t}-R P_{t-1}>0$, or losses, $P_{t}+\pi_{t}-R P_{t-1}<0$, from investing in one unit of equity. There is also an indirect channel from the impact that equity price has on the R\&D production through (15) and thereby the number of varieties in every period. This indirect channel works by determining both the level of wages, $\frac{\Gamma}{\alpha} \phi_{t} A_{t-1}$, and level of excess capital gains or losses, $\left(P_{t}+\pi_{t}-R P_{t-1}\right) A_{t}$.

Finally, using $X_{t}=\int_{0}^{A_{t}} \eta x_{t}(j) d j,(11),(12),(19),(20),(21)$ in the goods market clearing condition (11), gives the free-entry condition for R\&D production (see (14)). This confirms that the goods market clears in every period, which completes the equilibrium outcomes of the model. 


\subsection{Impact of optimism}

\subsubsection{Temporary optimism and consumption gains}

This section addresses the main question of the paper by examining the impact that temporary optimism in the equity market has on economic allocations. It analyses how the release of a single optimistic public signal affects the consumption of different generations. Optimism takes place when there are positive errors in the public signals, i.e., $\tilde{\phi}_{s}>\phi_{s}$ for some period $s$.

Assume throughout that $\phi_{t}=\bar{\phi}=\phi$ for every period $t$. A single optimistic public signal is released in period $t=\tau$ regarding productivity $T$ periods ahead, $\tilde{\phi}_{\tau}=\phi_{\tau+T}+\varepsilon_{\tilde{\phi}, \tau}>\phi$, while $\tilde{\phi}_{t}=\phi$ for every $t \neq \tau$. The degree of optimism is captured by a parameter $\kappa>0$, which is defined as the percentage error in the public signal, $\kappa \equiv \frac{\tilde{\phi}_{\tau}-\phi}{\phi}=\frac{\varepsilon_{\tilde{\phi}, \tau}}{\phi}$.

Given the assumptions, by (17) the equilibrium equity price in the model economy is

$$
\begin{aligned}
P_{\tau+k} & =\frac{\Gamma \phi}{R-1}+z \kappa \frac{\Gamma \phi}{R^{T-k}}, \text { for } k \in\{0, \ldots, T-1\}, \\
P_{t} & =\frac{\Gamma \phi}{R-1}, \text { for } t<\tau \text { and } t \geq \tau+T,
\end{aligned}
$$

while in the PI economy, the equity price (see equation (18)) stays constant at

$$
P_{t}^{P I}=P^{P I} \equiv \frac{\Gamma \phi}{R-1}, \forall t
$$

The optimistic public signal enters investors' expectations on the date it is released, $t=\tau$, and remains informative for $T$ periods, i.e., until $t=\tau+T-1$. During these periods, the equilibrium equity price remains above the PI one due to the positive error in consumers' beliefs about profits in period $\tau+T$. In period $t=\tau+T$, the optimistic beliefs about $\phi_{\tau+T}$ are proven to be wrong and in the absence of any further errors in public information, equity price returns to its initial level that is the same as in the PI economy.

Given the equilibrium path of prices, equation (21) fully specifies the path for aggregate consumption. In particular, from the equity price in PI economy (23) 
and profits (12), it is straightforward that there are no excess capital gains or losses in the PI economy, i.e., $P_{t}+\pi_{t}-R P_{t-1}=0$. Consumption in PI economy is determined by the risk-free return on wages and grows at the constant $\mathrm{R} \& \mathrm{D}$ growth rate $g_{A}^{P I}=\lambda^{\frac{1}{1-\rho}}\left(P^{P I}\right)^{\frac{\rho}{1-\rho}}$.

Further, from (15) and (22), R\&D growth in the model economy is greater than in the PI economy for the same $T$ periods that its equity prices exceed these in the PI economy, i.e., $g_{A, t+k}>g_{A}^{P I}$ for $k \in\{0, \ldots, T-1\}$. In turn, inspection of the path of consumption (21) suggests a potential trade-off between higher wages and excess capital losses. The following proposition summarizes the outcome of the interplay of the direct and indirect effects that optimism has on the consumption (21) of each generation.

Proposition 1 When $T>1, \phi_{t}=\bar{\phi}=\phi, \forall t$ and consumers receive a single optimistic public signal in period $t=\tau$, with error $\varepsilon_{\tilde{\phi}, \tau}=\kappa \phi$, for $\kappa>0$, then aggregate consumption in the model economy is at least as high as in the PI economy

$$
C_{t} \geq C_{t}^{P I}
$$

for all periods, except $t=\tau+T$. In period $t=\tau+T$, the comparison of consumption between the model and PI economy is ambiguous and depends on the parameters of the model.

\section{Proof. See Appendix A}

This result is driven by the positive indirect effect that higher equity prices have on consumption through higher R\&D growth. The level of $R \& D$ in the model economy is higher than in the PI economy from $t=\tau+1$ onwards, and all generations of consumers consuming from period $t=\tau+2$ onwards receive higher wages compared to consumers in the PI economy.

At the same time, equity prices have a direct effect on the path of excess capital returns. This effect is present only for two generations. It is positive for the generation consuming in period $t=\tau$, which sells its equity holdings in the first period that equity price increases because of the optimistic public signal. This generation has higher consumption than the PI one, solely due to receiving excess capital gains. 

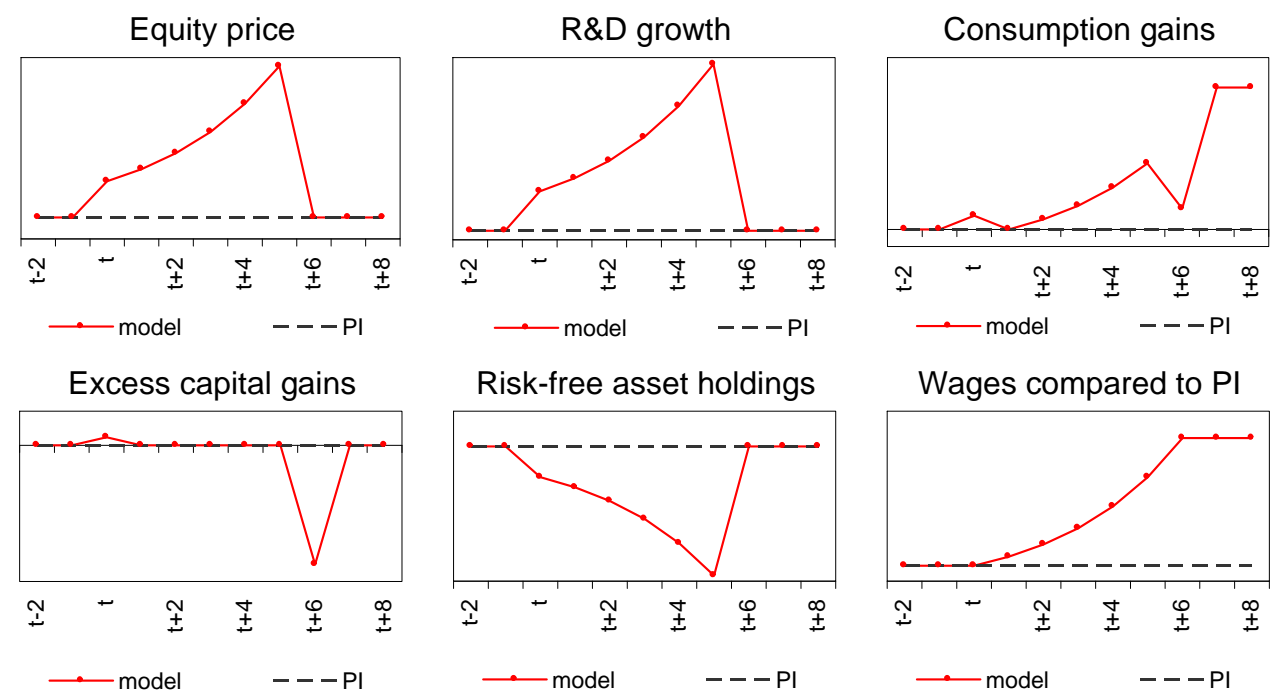

Figure 3: The impact of optimism on main economic variables.

It is negative for the generation consuming in period $t=\tau+T$, which is the only one receiving excess capital losses. This generation faces high equity prices when investing, but it consumes when optimism disappears and prices return to their original level. How much consumption decreases depends on the indirect impact of optimism and also through the expansion of the size of equity market, i.e., $A_{\tau+T}$.

The absence of excess capital returns for the generations consuming between $t=\tau+1$ and $t=\tau+T-1$ is because in this setting there is only public information. As a result, the investors' average beliefs coincide with the public signal and they do not learn about the true productivity in period $\tau+T$ from any other source before this period arrives. This assumption is relaxed in the Sections 4.1 and 4.2 where private information is introduced. Figure 3 considers the case of a singlerelease optimistic signal in period $t$ for $T=6$ and illustrates its impact on economic variables of interest. ${ }^{20}$

\footnotetext{
${ }^{20}$ The variables are "Equity price" - $P_{t}$; "R\&D growth" - $g_{A, t}$; "Consumption gains" $-C_{t} / C_{t}^{P I}$, "Excess capital gains" - $\left(P_{t}+\pi_{t}-R P_{t-1}\right) A_{t}$; "Risk-asset holdings" $-M_{t} /\left(M_{t}+H_{t} A_{t+1}\right)$ and "Wages compared to PI" $-w_{t-1} / w_{t-1}^{P I}$. Parameters are chosen for purely illustrative purposes, with $\rho=0.8$ and $\alpha=0.3$.
} 


\subsubsection{Welfare gains}

Proposition 1 above reveals that equity market optimism involves important tradeoffs. First, there is an intergenerational consumption trade-off. Second, there is an intratemporal trade-off concerning the generation consuming in period $\tau+T$. This generation assumes the entire cost of raising $\mathrm{R} \& \mathrm{D}$ investment for $T$ periods through excess capital losses, but gains though higher wages. To answer the question whether there is scope for welfare improvement in the presence of optimism, the criterion is Pareto improvement over the PI economy in the consumption of each generation. A sufficient condition for this is the one ensuring no net losses for the consumption of generation $\tau+T$.

Corollary 1.1 Assume that $T>1$ and $\rho>\bar{\rho} .^{21}$ Then, there exists some degree of optimism, $\kappa>0$, such that no generation of consumers is worse off compared to the $P I$ economy, $C_{t} \geq C_{t}^{P I}$, for any $t$. Furthermore, the higher is $T$, the higher is $\kappa$.

Proof. See Appendix B.

Corollary 1.1 suggests that the net effect of optimism on $C_{\tau+T}$ depends first on the degree of optimism $\kappa$, second, on the model's parameters related to the productivity of $\mathrm{R} \& \mathrm{D}$ and elasticity of $\mathrm{R} \& \mathrm{D}$ production with respect to investment $\rho$, and finally, on the length of horizon that the optimistic public signal affects expectations $T$.

The necessary condition for Pareto improvement of the model economy is that a small degree of optimism has a big R\&D productivity outcome. In such environment, the increase of R\&D investment bears a very low cost in terms of (unit) excess capital losses, while it generates high wage returns. The length of the period during which optimism is present is also highly important. The larger is $T$, the higher is the likelihood of Pareto improvement due to optimism. This is because the productivity gains from optimism are accumulated over a longer time period and therefore suffice to cover higher excess capital losses. ${ }^{22}$

In order to understand what allows optimism in equity market to be potentially

\footnotetext{
${ }^{21}$ Namely $\bar{\rho}$ solves $\frac{R-1}{R} \frac{\bar{\rho}}{1-\bar{\rho}}=\alpha \frac{\left(1+\lambda^{\frac{1}{1-\bar{\rho}}}\left(\frac{\Gamma \phi}{R-1}\right)^{\frac{\bar{\rho}}{1-\bar{\rho}}}\right)^{2}}{\lambda^{\frac{1}{1-\bar{\rho}}}\left(\frac{\Gamma \phi}{R-1}\right)^{\frac{\bar{\rho}}{1-\bar{\rho}}}}$. See Appendix B for details.

${ }^{22}$ As an illustration, when $T=1$, then the generation consuming in $\tau+1$ finances the higher R\&D, but cannot yet benefit in terms of higher wages. As a result, its consumption is strictly lower than in the PI economy.
} 
Pareto improving, it is useful to compare the PI economy with the social planner's solution. The social planner maximizes consumption of all generations,

$$
W_{1}=\sum_{t=1}^{\infty} \frac{1}{R^{t-1}} C_{t}
$$

on a steady-state path, where the initial period is $t=1, M_{0}, A_{1}>0$ are given and technology evolves according to $A_{t+1}-A_{t}=\lambda I_{t}^{\rho} A_{t}^{1-\rho}$ (see equations (6) and (7)). ${ }^{23}$

Comparing the valuation of firms listed in the PI economy's equity market to their social value leads to the following Corollary.

Corollary 1.2 The social value of an additional unit of $R \mathscr{E} D, P^{S P}$, is always higher than the private one, $P^{P I}$, i.e.,

$$
\frac{P^{S P}}{P^{P I}}=\frac{1}{\alpha^{\frac{1}{1-\alpha}}} \frac{R-1}{R-1-(1-\rho) g_{A}^{S P}}>1 .
$$

Proof. See Appendix .

Corollary 1.2 shows that equity is "underpriced" in the PI economy. In particular, the return from equity of any individual intermediate-good firm is the future profit flow of that firm. However this does not compensate for increasing productivity for all future R\&D producers. Furthermore, this does not compensate for the positive effect of a new variety on the final good productivity. Therefore, both the monopolistic distortion and the positive spillover effects imply that the private return to $\mathrm{R} \& \mathrm{D}$ investment is lower than its social return.

More specifically, the first term, $\alpha^{-\frac{1}{1-\alpha}}$, in (24) captures the effect of monopolistic distortion, which implies that the production of intermediate goods in the PI economy is too low. ${ }^{24}$ The second term, $\frac{R-1}{R-1-(1-\rho) g_{A}^{S P}}$, highlights that the social discount rate is lower than the private one. The effective discount rate accounts for the knowledge externality's growth effect, given by the product of optimal growth rate, $g_{A}^{S P}$, with the elasticity of new varieties production to the existent knowledge

\footnotetext{
${ }^{23}$ The social planner is assumed to discount the consumption of future generations with the riskfree interest rate. This is driven by the assumption that the risk-free interest rate is exogenous and guarantees that the social planner does not accummulate infinitely positive or negative risk-free asset holdings.
}

${ }^{24}$ Appendix C shows that $x^{S P}=\left(\frac{\alpha}{\eta}\right)^{\frac{1}{1-\alpha}} \phi L$. This compares to (11) through $\frac{x^{S P}}{x^{P I}}=\frac{1}{\alpha^{\frac{1}{1-\alpha}}}$. 
stock, $1-\rho$.

However, the low private return to R\&D in the PI economy does not necessarily imply that there is also underinvestment in $\mathrm{R} \& \mathrm{D}$. This is because of the negative congestion externality of any individual R\&D producer on others' productivity. Therefore, increasing R\&D investment and thereby R\&D growth (see (15)) is not socially optimal.

Corollary 1.3 A sufficient condition that there is underinvestment in RESD in PI economy compared to the socially optimal one is $\rho \geq \alpha^{\frac{1}{1-\alpha}}$. Under this condition

$$
\iota^{S P}>\iota^{P I} \Leftrightarrow g_{A}^{S P}>g_{A}^{P I},
$$

where $\iota^{S P} \equiv \frac{I_{t}^{S P}}{A_{t}^{S P}}$ and $\iota^{P I} \equiv \frac{I_{t}^{P I}}{A_{t}^{P I}}$.

Proof. See Appendix D.

This result requires that the elasticity of $R \& D$ production with respect to investment $\rho$ is not too low. This paper assumes throughout the condition of Corollary 1.3, making it always beneficial to increase R\&D investment. While such incentives are absent in the market, they are created by the temporary equity market optimism. This brings R\&D investment in the model economy temporarily closer to the socially desirable level, so that there is scope for Pareto improvement.

\section{The Role of Private Information}

In reality, investors use information from multiple sources, both public and private. In this spirit, this section extends the baseline model by considering investors with both public and heterogeneous private information, and shows that the main results of Section 3 are robust. Furthermore, it discusses how the short investors' horizons result in higher order expectations and analyzes their role, while carefully distinguishing the learning factor.

It is assumed that in every period $t$, each investor $i$ receives not only public signals about productivity in period $t+T$, as discussed in Section 2.1, but also a private signal, i.e., he receives $\nu_{t}(i)=\phi_{t+T}+\varepsilon_{\nu, t}(i)$, where $\varepsilon_{\nu, t}(i) \sim \mathcal{N}\left(0,1 / \beta_{\nu}\right)$. 
Each investor also "inherits" an entire sequence of historical private signals from his "ancestors" indexed with $i$. Therefore, an investor $i$ trading in $t$ uses the set of private signals that are informative about future profits $\left\{\nu_{t-T+1}(i), . ., \nu_{t}(i)\right\}$. Private signals are uncorrelated over time, across investors and with other shocks.

Without any further assumptions, the presence of private information would make equity prices fully revealing, i.e., equal to $P^{P I}$ as shown by Grossman and Stiglitz (1980). Prices can still deviate from fundamentals and become informative signals on their own, only if there is an additional source of uncertainty. This is achieved by introducing noise traders, who in every period $t$ trade a random quantity of equity $s_{t} \sim N\left(0,1 / \beta_{s}\right)$, where $s_{t}$ is uncorrelated over time and with other shocks. ${ }^{25}$ Therefore, a negative noise trading shock, $s_{t}<0$, corresponds to higher aggregate demand for the available equity, $A_{t+1}$, so that equilibrium equity price is determined by the market clearing condition

$$
\int_{0}^{1} h_{t}(i) d i-s_{t}=H_{t}-s_{t}=0
$$

To conclude, in period $t$ a rational investor $i$ receives information from three sources: public signals, private signals and equity prices, so that the information set that is relevant is

$$
\Omega_{t}(i)=\left\{\nu_{t-T+1}(i), . ., \nu_{t}(i), \tilde{\phi}_{t-T+1}, . ., \tilde{\phi}_{t}, P_{t-T+1}, . ., P_{t}, \bar{\phi}\right\}
$$

Figure 4 corresponds the timing of the arrival of each type of signal to the future profits for which it provides information.

From (2), the optimal equity demand by an investor $i$ is

$$
h_{t}(i)=\frac{E\left[P_{t+1}+\pi_{t+k} \mid \Omega_{t}(i)\right]-R P_{t}}{\gamma V}
$$

where $V \equiv \operatorname{Var}\left[P_{t+1}+\pi_{t+k} \mid \Omega_{t}(i)\right]$ is constant over time and across investors. This is a guess to be verified in equilibrium. Aggregating (27) across investors and using

\footnotetext{
${ }^{25}$ The noise traders face the same resource constraints as the rational consumers, with the difference that they earn no wage income. This assumption does not affect the results, given the CARA utility and abcence of any short sales or borrowing constraints.
} 


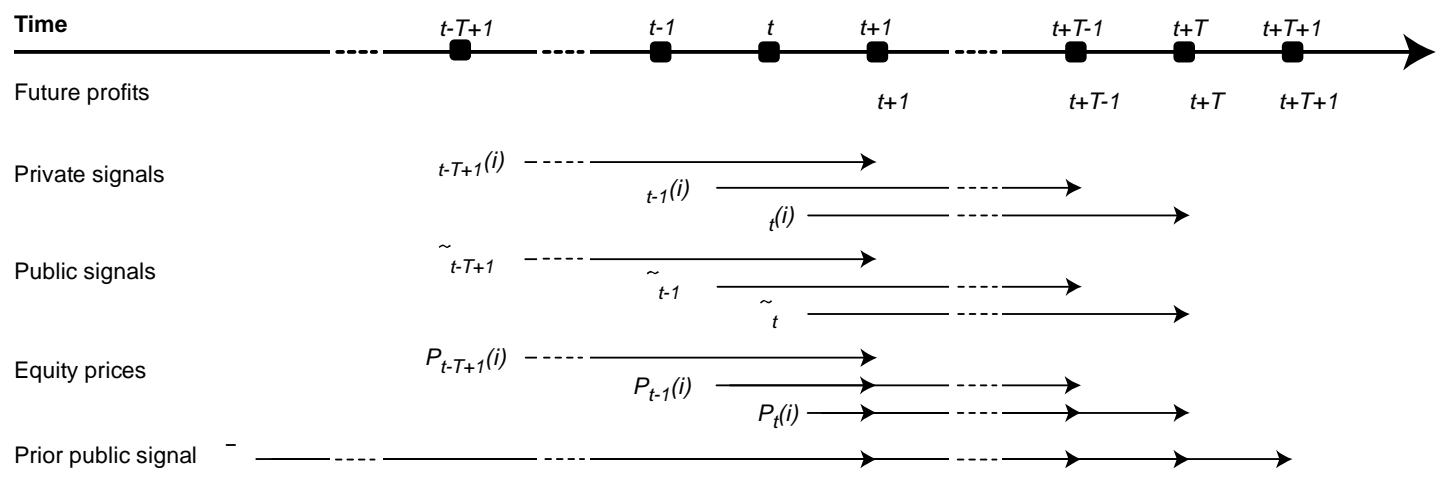

Figure 4: Information available in period $t$ by the time of arrival.

it into (25), the equilibrium equity price is

$$
P_{t}=\frac{\bar{E}\left[P_{t+1}+\pi_{t+1} \mid \Omega_{t}\right]}{R}-\frac{\gamma V}{R} s_{t}
$$

where $\bar{E}\left[P_{t+1}+\pi_{t+k} \mid \Omega_{t}\right] \equiv \int_{0}^{1} E\left[P_{t+1}+\pi_{t+k} \mid \Omega_{t}(i)\right] d i$ is the average expectation across investors (market expectation).

It is straightforward that introducing private information has no effect on the production-side equilibrium allocations of Section 3.1.

\subsection{Naive expectations}

Before analyzing the properties of the fully rational expectations equilibrium, this section considers the case where investors do not take into account the information revealed in equity prices. Their "naive" expectations are formed based on the information set

$$
\Omega_{N, t}(i)=\left\{\nu_{t-T+1}(i), . ., \nu_{t}(i), \tilde{\phi}_{t-T+1}, . ., \tilde{\phi}_{t}, \bar{\phi}\right\}
$$

Examining such setting has several advantages. First, it delivers analytical results for the equilibrium equity price and the impact of the private information. Second, it separates the effect of higher order beliefs from learning. This is because investors with naive expectations do not learn any additional information about $\phi_{t+T}$ after period $t$. 
Proposition 2 When investors have naive expectations, the equilibrium equity price is

$P_{N, t}=\sum_{k=1}^{T}\left[\frac{\sigma^{k}}{R^{k}} \Gamma \phi_{t+k}+\frac{1-\sigma^{k}}{R^{k}}\left(z \Gamma \tilde{\phi}_{t-T+k}+(1-z) \Gamma \bar{\phi}\right)\right]+\frac{\Gamma \bar{\phi}}{R^{T}(R-1)}-\frac{\gamma V}{R} s_{t}$,

where $\sigma \equiv \frac{\beta_{\nu}}{\beta_{\phi}+\beta_{\tilde{\phi}}+\beta_{\nu}}, z \equiv \frac{\beta_{\tilde{\phi}}}{\beta_{\phi}+\beta_{\tilde{\phi}}}$ and $V=V\left(\beta_{\phi}, \beta_{\hat{\phi}}, \beta_{v}, \beta_{s}, \gamma ; R, \Gamma\right)$.

Proof. See Appendix E.

Proposition 2 shows that the equilibrium equity price is a linear function of future productivity, public signals and noise trading in period $t$. Unlike the private signals, errors in the public signals do not average out across investors. As a result, public information has a persistent impact on the equity price. In particular, a periodic public signal $\tilde{\phi}_{t}$ remains informative and thereby affects equity price in all periods until $t+T$.

While the presence of private information does not make public information redundant, it does reduce the impact of public signals on equity price. When only public information is available as in Section 3.1.3, then for example $\frac{\partial P_{t}}{\partial \tilde{\phi}_{t-T+k}}=\frac{z \Gamma}{R^{k}}$, which is higher than in the case of naive expectations, $\frac{\partial P_{N, t}}{\partial \tilde{\phi}_{t-T+k}}=\frac{z \Gamma\left(1-\sigma^{k}\right)}{R^{k}}$. In response, from (15), R\&D growth becomes also less responsive to public signals.

The assumption that consumers are short-lived brings forth the importance of higher order beliefs. In order to see this, define the present discounted value of the average ("market") expectations of future profits as

$$
\overline{\mathcal{D}}_{N, t} \equiv \sum_{k=1}^{\infty} \frac{\bar{E}\left[\pi_{t+k} \mid \Omega_{N, t}\right]}{R^{k}}
$$

where $\bar{E}\left[\pi_{t+k} \mid \Omega_{N, t}\right]=\int_{0}^{1} E\left[\pi_{t+k} \mid \Omega_{N, t}(i)\right] d i$ is the average expectation of profits in period $t+k$ for $k>0$. Since the average expectation of some productivity $\phi_{t+k}$ for $k \in\{1, . . T\}$, is

$$
\bar{E}\left[\phi_{t+k} \mid \Omega_{N, t}(i)\right]=\frac{\beta_{\phi} \bar{\phi}+\beta_{\tilde{\phi}} \tilde{\phi}_{t-T+k}+\beta_{\nu} \phi_{t+k}}{\beta_{\phi}+\beta_{\tilde{\phi}}+\beta_{\nu}}=\sigma \phi_{t+k}+(1-\sigma)\left[z \tilde{\phi}_{t-T+k}+(1-z) \bar{\phi}\right]
$$


equity price reacts more to changes in the public signal for $\phi_{t+k}$ compared to the average expectation of profits, i.e., $\frac{\partial P_{N, t}}{\partial \tilde{\phi}_{t-T+k}}=\frac{z \Gamma\left(1-\sigma^{k}\right)}{R^{k}}>\frac{\partial \overline{\mathcal{D}}_{N, t}}{\partial \tilde{\phi}_{t-T+k}}=\frac{z \Gamma(1-\sigma)}{R^{k}}$. In contrast, equity price reacts less to changes in the true productivity compared to the average expectation of profits, i.e., $\frac{\partial \overline{\mathcal{D}}_{N, t}}{\partial \phi_{t+k}}=\frac{z \Gamma \sigma}{R^{k}}>\frac{z \Gamma \sigma^{k}}{R^{k}}=\frac{\partial P_{N, t}}{\partial \phi_{t+k}}$.

The reason for this result is that public signals reveal information not only about future profits, but also about the expectations of future generations of investors (i.e., future market expectations). Knowing this, short-lived investors put relatively more weight on the public signal because investors care only about next period's returns. The generation of a higher order wedge between the equity price and the underlying average expectation of fundamentals, $\overline{\mathcal{D}}_{N, t}$, is analyzed extensively in Allen, Morris, and Shin (2006) and Bacchetta and Wincoop (2007). In contrast, there is no room for such wedge, when investors are long-lived and equity price equals the present discounted value of expected profits. As shown in Section 3.1.3, this is also the case when investors are short-lived but without heterogeneous private information. ${ }^{26}$

As in Section 3.2.1, it is assumed that a single optimistic public signal $\tilde{\phi}_{\tau}=$ $(1+\kappa) \phi, \kappa>0$ is released, while $\phi_{t}=\phi$ for every period $t$. Noise trading is also assumed to realize at its mean value $s_{t}=0$ for any $t$. From (29), the equity price increases above $P^{P I}$ from period $\tau$ until $\tau+T-1$

$$
P_{N, \tau+k}=\frac{\Gamma \phi}{R-1}+z \kappa\left(1-\sigma^{T-k}\right) \frac{\Gamma \phi}{R^{T-k}}, \text { for } k \in\{0, . ., T-1\}
$$

and in response R\&D growth increases (from results of Section 3.1). As highlighted already, private information decreases the impact of temporary optimism on equity prices and R\&D growth (compare to (22)).

In view of the equity price path, all generations consuming between periods $\tau+1$ and $\tau+T$ share the cost of higher R\&D investment in this period. Using (32), their excess capital losses are $P_{N, \tau+k}+\Gamma \phi-R P_{N, \tau+k-1}=-\sigma^{T-k} z \kappa(1-\sigma) \frac{\Gamma \phi}{R^{T-k}}<0$ for $k \in\{1, \ldots, T-1\}$ and $P_{N, \tau+T}+\Gamma \phi-R P_{N, \tau+T-1}=-z \kappa(1-\sigma) \Gamma \phi<0$. This is driven by higher order beliefs that imply a monotonically decreasing weight for the public signal in the average expectations, $z\left(1-\sigma^{T-k}\right)$, for all periods that it

\footnotetext{
${ }^{26}$ This highlights that the assumption that investors are short-lived does not affect the asset allocation decisions in the baseline model.
} 
remains informative, i.e., until $\tau+T$.

This result is in sharp contrast to the case of public information alone (Section 3.2.1) and the case where investors with naive expectations are long-lived. In both cases, the absence of higher order beliefs implies a constant weight on the public signal. As a result, investors do not obtain excess capital losses before period $\tau+T .{ }^{27}$ In the absence of learning new information about $\phi_{\tau+T}$ before $\tau+T, P_{\tau}$ adjusts just enough to accommodate the new information already in period $\tau$. With shorthorizoned investors with naive expectations, $P_{\tau}$ increases more than the expected value of profits. The short investment horizons that give rise to higher order beliefs is the sole reason for excess capital losses before period $\tau+T$.

To summarize, all generations investing between $\tau$ and $\tau+T$ receive excess capital losses, while only the ones consuming from $\tau+2$ onwards benefit from higher wages. Notably, the generation consuming in $t+1$, does not benefit from higher wages, while it does receive excess capital losses, so (21) implies $C_{N, \tau+1}=$ $-\sigma^{T-1} z \kappa(1-\sigma) \frac{\Gamma \phi}{R^{T-1}} A_{N, \tau+1}+\frac{R}{\alpha} \Gamma \phi A_{\tau}<C_{N, \tau+1}^{P I}=\frac{R}{\alpha} \Gamma \phi A_{\tau}$.

As a final note, (29) shows that temporarily higher equity price and R\&D growth may also result from a noise trading shock that increases equity demand, $s_{t}<0$. However, even if the impulse response of $P_{N, \tau}$ in $s_{\tau}$ and $\tilde{\phi}_{\tau}$ is identical, the impact of optimism on R\&D growth and output would be higher when $T>1$. This is because the impact of optimism is persistent so that equity price remains higher until $\tau+T-1$, while that of a noise trading shock price disappears in $\tau+1$. Section 4.2 shows that the impact of a noise-trading shock gains the persistence of optimism when investors take into account the history of prices.

\subsection{Rational expectations}

Fully rational investors make expectations about future productivity using also the information revealed in prices, i.e., their information set is (26). In such a case, there is no analytical solution for the equilibrium equity price. Appendix F describes the algorithm for the numerical solution of the equilibrium equity price and shows how,

\footnotetext{
${ }^{27}$ Long-lived investors price equity according to their expected value of profits. Using (30) and (31) $\overline{\mathcal{D}}_{N, \tau+k}=\frac{\Gamma \phi}{R-1}+z \kappa(1-\sigma) \frac{\Gamma \phi}{R^{T-k}}$ and $\overline{\mathcal{D}}_{N, \tau+k}+\Gamma \phi-R \bar{\pi}_{N, P V, \tau+k-1}=0$ for $k \in\{1, \ldots, T-1\}$.
} 

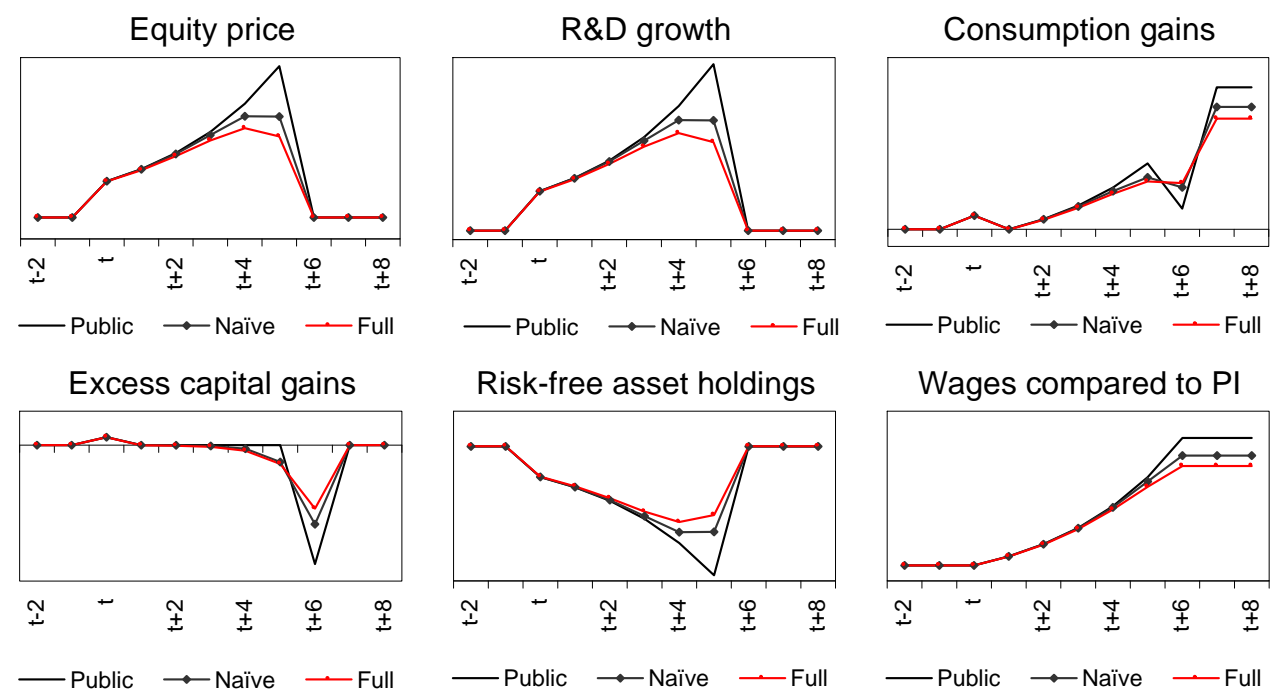

Figure 5: The effect of private information (naive and rational expectations)

similar to the case of naive expectations (29), equity price remains a linear function of future productivity, public signals and noise trading, i.e.,

$$
P_{t}=\Gamma \sum_{k=1}^{T}\left(\mu_{k} \phi_{t+k}+z \hat{\mu}_{k} \tilde{\phi}_{t-T+k}+(1-z) \hat{\mu}_{k} \bar{\phi}\right)+\bar{\mu} \bar{\phi}-\sum_{k=1}^{T} \mu_{s, k} s_{t-T+k} .
$$

Figure 5 considers a single optimistic signal in period $\tau$ for $T=6$. It compares the reaction of economic variables in three different settings: 1) public information only, 2) private and public information with naive expectations and 3) private and public information with rational expectations. The variables are defined as in Figure 3. The figure illustrates how the main predictions of Section 3 regarding the impact of temporary optimism remain robust to the addition of private information. Whether with naive or fully rational expectations, private information reduces the magnitude of the impact of optimism on real economic outcomes.

The main difference between naive and rational expectations is that investors learn new information about $\phi_{\tau+T}$ after the optimistic public signal shock in period $\tau, \tilde{\phi}_{\tau}$, through the price signals. As illustrated in Figure 4 , all prices $P_{\tau}, \ldots, P_{\tau+T-1}$ in the optimistic equity market provide (noisy) information for $\phi_{\tau+T}$. The effect of learning on rational expectations is that equity price reacts less to temporary public signals compared to the case of naive expectations, while the weight on the optimistic 

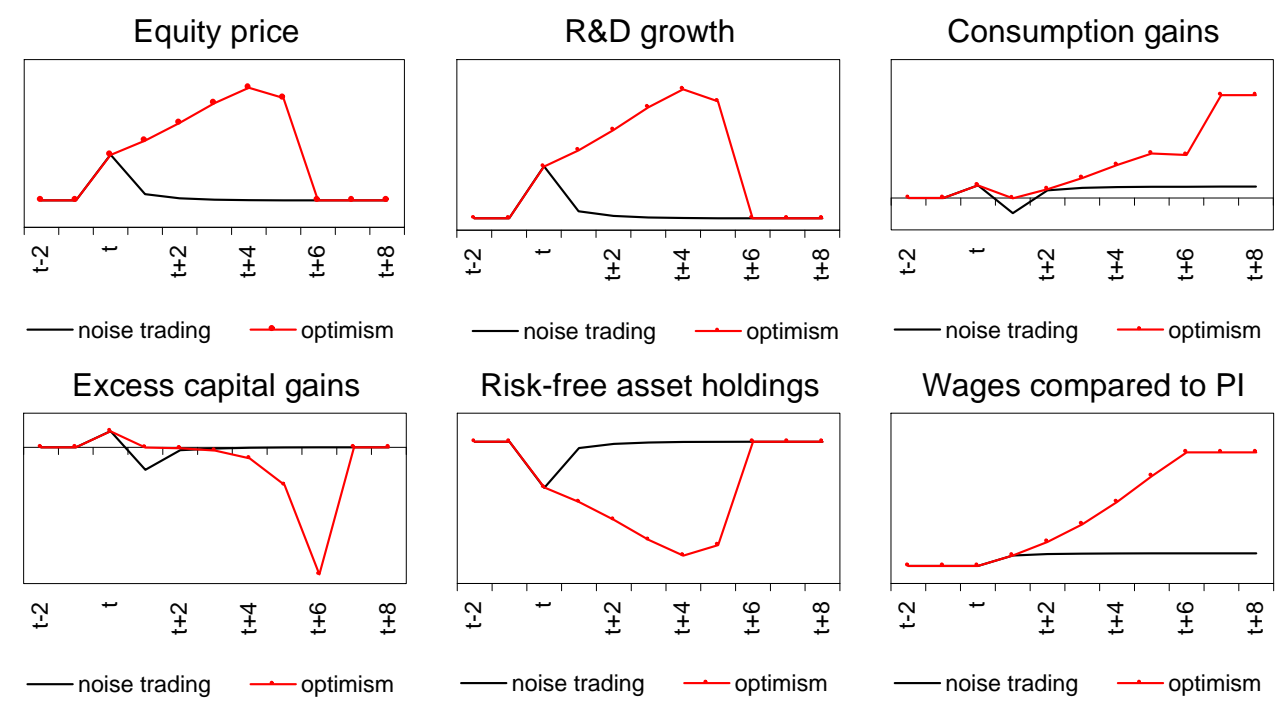

Figure 6: Comparison of the impact of excess demand by noise traders and a positive public signal.

public signal decreases faster. Learning complements the role of higher order beliefs also in driving excess capital losses for all generations consuming between periods $t+1$ and $t+6$, since prices also signal higher $\phi_{\tau+T}$.

Another effect that is specific to rational expectations is that historical noise trading shocks affect equity price as well. This is because when a noise trading shock $s_{\tau}$ is realized, then its direct effect on $P_{\tau}$ constitutes also an impact on the signal that this price provides for future productivity for a $T$-long period. Therefore, in contrast to the case of naive expectations, noise trading shocks have the same persistence as a public signal shock. However, while a public signal enters expectations with a decreasing weight, the opposite is true for the noise trading shock. This is because once the noise trading becomes historical, it enters expectations only indirectly through the noisy historical price signals. As Figure 6 illustrates, the compounded effect on real outcomes following a public signal is expected to be higher than that of a noise trading shock when the two shocks have the same contemporaneous impact on equity price. 


\subsection{Persistent optimism}

As shown in Sections 4.1 and 4.2, not all generations of investors can become better off following the release of a single public signal. This is because the generation consuming in $\tau+1$ receives capital losses without benefiting from the higher R\&D growth through wages.

Therefore, the necessary condition for a Pareto improvement is that optimism is persistent, i.e., a positive public signal has to be released in subsequent periods. Without loss of generality, this is proven for the simplest case of an infinite-horizon model, where investors get public signals about productivity two periods ahead, $T=2 .^{28}$

Proposition 3 Assume that actual productivity stays constant and equal to its longterm value, $\phi_{t}=\bar{\phi}=\phi$, and noise trading is at its mean value each period, $s_{t}=0$, for any $t$. When there are positive public signal shocks in two consecutive periods, $\tilde{\phi}_{\tau}=\phi+\varepsilon_{\tilde{\phi}_{\tau}}$ and $\tilde{\phi}_{\tau+1}=\phi+\varepsilon_{\tilde{\phi}_{\tau+1}}$, while $\varepsilon_{\tilde{\phi}_{\tau+1-k}}=\varepsilon_{\tilde{\phi}_{\tau+k}}=0$ for any $k \geq 2$, then there exist $\varepsilon_{\tilde{\phi}_{\tau}}>0$ and $\varepsilon_{\tilde{\phi}_{\tau+1}}>0$ such that aggregate consumption in the model economy is at least as high as in the one with perfect information in every period, i.e., $C_{t} \geq C_{t}^{P I}$ for any $t$.

\section{Proof. See Appendix G.}

The result of Proposition 3 relies in a second public signal that is sufficiently high to ensure that consumers in period $\tau+1$ have at least as high consumption as in the PI economy. The role of the subsequent public signal is to increase the equity price between $\tau$ and $\tau+1$ so that it prevents the realization of excess capital losses for this generation. This shifts the burden of the excess capital losses on the generations consuming in periods $\tau+2$ and $\tau+3$, who already experience the $\mathrm{R} \& \mathrm{D}$ driven output expansion. Therefore, these generations could offset their equity holdings' losses with their wage gains. For standard arguments, all other generations of consumers are strictly better off in the presence of persistent optimism. The sufficient conditions

\footnotetext{
${ }^{28}$ Assuming $T>2$ would not introduce any further force that affects whether there is scope for welfare gains in the presence of optimism. It would only require that optimism is persistent over the $T$-long period. The hint for this intuition lies already in the results of Section 3.2.2, which state that the higher is $T$ then the less strict are the conditions for Patero improvement.
} 
for welfare gains are a low degree of optimism in the public signals and congestion in the R\&D production $\rho .^{29}$

\section{Conclusions}

This paper builds a general equilibrium framework to analyze the effect of equity market optimism on aggregate welfare, given the trade-off between excess capital losses from the equity holding of $\mathrm{R} \& \mathrm{D}$ intensive firms and the productivity gains from the new $R \& D$ products. The main result is that optimism can increase consumption income of all generations, including the ones receiving maximum losses from equity trading.

This result is driven from the wedge between the private and social returns to $R \& D$ primarily due to the presence of the knowledge externality in $R \& D$ production. Hence, an equity contract which provides investors with claims only on the future flow of profits, brings in excess capital losses due to overinvestment in R\&D at the firm-level. However, at the aggregate level, R\&D investment rises temporarily closer to its socially optimal level, which has a permanent effect on the level of productivity of the economy, which brings wage gains for all generations.

Welfare gains take place when a small degree of optimism results in high $R \& D$ production. This means that productivity of $R \& D$ needs to be high (i.e., strong knowledge and/or small congestion effect). In view of this, the benefits of optimism are more likely in the case of the emergence of "new industries" (e.g., information technologies), rather than "old industries" (e.g., real estate). For public signals to have a growth generating role, they need to be credible (not infinitely noisy). Welfare gains become more likely when optimism is persistent, since this implies that the costs of optimism are spread over more generations and allows the wage gains to compensate for the costs.

In view of these results the model reviews the public scepticism regarding the role of policy makers in episodes like the late 1990s: "A less forgivable mistake was that

\footnotetext{
${ }^{29}$ This regulates the strength of decreasing returns to $R \& D$ investment. Consider the extreme case of congestion, i.e., $\rho \rightarrow 0$. Then R\&D growth is no longer endogenous, $g_{A_{t}} \rightarrow \lambda$, as any additional funds have zero additional effect on the underlying productivity. Therefore, market optimism does not affect R\&D growth.
} 
Mr. Greenspan acted as something of a cheerleader for the 'new economy'. Even if some increase of productivity was real, his enthusiasm contributed to investors' euphoria. They seized on all of his comments to justify their bullishness about future profits" (The Economist, September 5, 2002).

As a first note, this model highlights the role of public information in coordinating expectation of equity market participants in achieving socially desirable outcomes. To the extent that policy makers can affect the equity market sentiment, as Mr. Greenspan arguably did, then optimism becomes an important policy instrument. Importantly, optimism has the feature of a innovative policy instrument, whether or not in control of policy makers. Indirectly, optimism "subsidizes" R\&D investment of individual R\&D producers that are financed by "taxing" the consumers in terms of excess capital losses. Unlike a system of direct taxes/subsidies, optimism is a purely market based mechanism and does not distort any incentives. Consumers are "voluntarily" taxed, and firms have incentives to invest the equity funds in R\&D. From the viewpoint of a policy maker, it requires no superior information at the firm-level R\&D production.

It suggests though that the policy maker has superior information regarding which new technologies/industries bear the scope for significant productivity gains. Care needs to be taken also for injecting the sufficient degree of optimism that would unravel these productivity gains. Also, the results suggest that optimism as an instrument at the hands of policy makers is not inexhaustible. The use of optimism injections comes at the cost of loss of credibility. This is especially due to the fact that policy makers have an incentive to transmit optimism to the equity market over the entire business cycle.

Considering the question whether equity market optimism can be good for welfare, the key message of this paper is that when evaluating any episode of equity overpricing, one needs to take into account its effect for R\&D activity and through this its long-run impact. The questions whether the late 1990s was an episode where the conditions for welfare gains were met, or whether Alan Greenspan standing as a "cheerleader" of the new economy benefited the United States or not, is left for empirical investigation. 


\section{A Proof of Proposition 1}

The proof starts with specifying the equilibrium $R \& D$ growth rate and consumption in PI economy. From (6) and (23), the growth rate in PI economy is constant at

$$
g_{A}^{P I} \equiv g_{A, t}^{P I}=\lambda^{\frac{1}{1-\rho}}\left(\frac{\Gamma \phi}{R-1}\right)^{\frac{\rho}{1-\rho}}
$$

Given that from (12) and (23), $P^{P I}+\pi_{t}=\frac{\Gamma \phi}{R-1}+\Gamma \phi=R \frac{\Gamma \phi}{R-1}=R P^{P I}$ and there are no excess capital gains (or losses) in PI economy. Therefore, aggregate consumption (21) simplifies to $C_{t}^{P I}=R w_{t-1}^{P I} L$. Using, $w_{t-1}^{P I}=(1-\alpha) Y_{t-1}^{P I}$ and (20) this can be expressed as

$$
C_{t}^{P I}=\frac{R}{\alpha} \Gamma \phi A_{t-1}^{P I}
$$

In the model economy, the equilibrium prices are given by (22). Given that $P_{\tau+k}>P^{P I}$ for $\forall k \in\{0, \ldots, T-1\}$ and $P_{t}=P^{P I}$ for any $t<\tau$ and $t \geq \tau+T$, the $\mathrm{R} \& \mathrm{D}$ growth rate $(15)$ is $g_{A, t}=g_{A}^{P I}, t<\tau$ and $t \geq \tau+T$, and $g_{A, \tau+k}>g_{A}^{P I}$, $\forall k \in\{0, \ldots, T-1\}$. As a result, $A_{t}>A_{t}^{P I}, \forall t>\tau$, so that $R w_{t-1} L=\frac{R}{\alpha} \Gamma \phi A_{t-1}>$ $\frac{R}{\alpha} \Gamma \phi A_{t-1}^{P I}, \forall t \geq \tau+2$.

Given the path of prices, the corresponding path of excess capital gains or losses is:

$$
\begin{aligned}
& \left(P_{t}+\pi_{t}-R P_{t-1}\right) A_{t}=0, \forall t \in \mathbb{Z}: t \neq \tau+1, \tau+T, \\
& \left(P_{\tau}+\pi_{\tau}-R P_{\tau-1}\right) A_{\tau}=\kappa z \frac{\Gamma \phi}{R^{T}} A_{\tau}, \\
& \left(P_{\tau+T}+\pi_{\tau+T}-R P_{\tau+T-1}\right) A_{\tau+T}=-\kappa z \Gamma \phi A_{\tau+T} .
\end{aligned}
$$

Consolidating the above information,

$$
\begin{aligned}
& C_{t}=C_{t}^{P I}, \forall t<\tau, \\
& C_{\tau}=\kappa z \frac{\Gamma \phi}{R^{T}}+\frac{R}{\alpha} \Gamma \phi A_{\tau-1}=\kappa z \frac{\Gamma \phi}{R^{T}}+C_{\tau}^{P I}>C_{\tau}^{P I}, \\
& C_{\tau+k}=\frac{R}{\alpha} \Gamma \phi A_{\tau+k-1}>\frac{R}{\alpha} \Gamma \phi A_{\tau+k-1}^{P I}=C_{\tau+k}^{P I}, \forall k \in\{2, \ldots, T-1\},
\end{aligned}
$$

In period $t=\tau+1$, there are no excess gains or losses and there are no realized 
wage benefits, so that

$$
C_{\tau+1}=\frac{R}{\alpha} \Gamma \phi A_{\tau}=C_{\tau+1}^{P I}
$$

while in period $t=\tau+T$, consumers on the one hand receive excess capital losses and on the other hand wage gains. They consume

$$
C_{\tau+T}=\frac{R}{\alpha} \Gamma \phi A_{\tau+T-1}-\kappa z \Gamma \phi A_{\tau+T}
$$

Whether this is higher or lower than in PI economy depends on the parameters of the model.

\section{B Proof of Corollary 1.1}

Given the results in Proposition 1, all generations of consumers gain from optimism iff $\frac{C_{\tau+T}}{C_{\tau+T}^{P I}} \geq 1$. For period $t=\tau+T-1$, the equilibrium equity price is $P_{\tau+T-1}=\frac{\Gamma \phi}{R-1}+z \kappa \frac{\Gamma \phi}{R}$, such that by (15) the $\mathrm{R} \& \mathrm{D}$ growth rate is $g_{A, \tau+T-1}=$ $\lambda^{\frac{1}{1-\rho}}\left(\frac{\Gamma \phi}{R-1}\right)^{\frac{\rho}{1-\rho}}\left(1+z \kappa \frac{R-1}{R}\right)^{\frac{\rho}{1-\rho}}=g_{A}^{P I}\left(1+z \kappa \frac{R-1}{R}\right)^{\frac{\rho}{1-\rho}}$. From (34) and (35), the condition $\frac{C_{\tau+T}}{C_{\tau+T}^{P I}} \geq 1$ can be expressed as

$$
\begin{aligned}
& G_{1}(\kappa, T) G_{2}(\kappa) \geq 1, \text { where } \\
& G_{1}(\kappa, T) \equiv \frac{A_{\tau+T-1}}{A_{\tau+T-1}^{P I}} \text { and } G_{2}(\kappa) \equiv 1-z \kappa \frac{\alpha}{R}\left[1+g_{A}^{P I}\left(1+z \kappa \frac{R-1}{R}\right)^{\frac{\rho}{1-\rho}}\right] .
\end{aligned}
$$

Since $A_{\tau+T}=\left(1+g_{A, \tau+T-1}\right) A_{\tau+T-1}$ and $A_{t}=A_{t}^{P I}, G_{1}(\kappa, T)=\frac{\prod_{k=\tau}^{\tau+T-2}\left(1+g_{A, k}\right)}{\left(1+g_{A}^{P I}\right)^{T-1}}$. Using, (15) and (22), $g_{A, k}=g_{A}^{P I}\left(1+z \kappa \frac{R-1}{R^{T-k+\tau}}\right)^{\frac{\rho}{1-\rho}}$ for any $k \in\{\tau, . ., \tau+T-2\}$. From here $g_{A, \tau+T-2}>g_{A, \tau+T-3}>\ldots>g_{A}^{P I}>0$, it is clear $G_{1}(\kappa, T)>1$ and $G_{1}(\kappa, 2)=\frac{1+g_{A, \tau+T-2}}{1+g_{A}^{P I}} \leq G_{1}(\kappa, T)$ for any $T \geq 2$. Therefore, a sufficient condition for (36) to hold is that

$$
F(\kappa) \equiv\left[1+g_{A}^{P I}\left(1+z \kappa \frac{R-1}{R^{2}}\right)^{\frac{\rho}{1-\rho}}\right] G_{2}(\kappa)-\left(1+g_{A}^{P I}\right) \geq 0
$$

One needs to investigate the conditions under which there exists $\kappa>0$, such 
that the above condition holds true. Note that $F(0)=0$ and $\lim _{\kappa \rightarrow \infty} F(\kappa)=-\infty .{ }^{30}$ Furthermore note that $F(\kappa)$ is continuous in $\kappa$. For the purpose of this proof, it is sufficient to exclude that $F(\kappa)<0$ for any $\kappa>0$. Therefore, it becomes sufficient that $F(\kappa)>0$ when making a small step away from $\kappa=0$, i.e., $F^{\prime}(0)>0$. Given that

$$
\begin{aligned}
F^{\prime}(\kappa) & =z \frac{R-1}{R^{2}} \frac{\rho}{1-\rho} g_{A}^{P I}\left(1+z \kappa \frac{R-1}{R^{2}}\right)^{\frac{\rho}{1-\rho}-1} G_{2}(\kappa)+ \\
& -z \frac{\alpha}{R}\left(1+g_{A}^{P I}\left(1+z \kappa \frac{R-1}{R^{2}}\right)^{\frac{\rho}{1-\rho}}\right)\left(1+g_{A}^{P I}\left(1+z \kappa \frac{R-1}{R}\right)^{\frac{\rho}{1-\rho}}\right) \\
& -z^{2} \kappa \frac{\alpha}{R} g_{A}^{P I} \frac{\rho}{1-\rho} \frac{R-1}{R}\left(1+g_{A}^{P I}\left(1+z \kappa \frac{R-1}{R^{2}}\right)^{\frac{\rho}{1-\rho}}\right)\left(1+z \kappa \frac{R-1}{R}\right)^{\frac{\rho}{1-\rho}-1},
\end{aligned}
$$

then the result is

$$
F^{\prime}(0)=z \frac{R-1}{R^{2}} \frac{\rho}{1-\rho} g_{A}^{P I}-z \frac{\alpha}{R}\left(1+g_{A}^{P I}\right)^{2}
$$

Therefore, $F^{\prime}(0)>0$ iff

$$
\frac{R-1}{R} \frac{\rho}{1-\rho}>\alpha \frac{\left(1+g_{A}^{P I}\right)^{2}}{g_{A}^{P I}}=\alpha \frac{\left(1+\lambda^{\frac{1}{1-\rho}}\left(\frac{\Gamma \phi}{R-1}\right)^{\frac{\rho}{1-\rho}}\right)^{2}}{\lambda^{\frac{1}{1-\rho}}\left(\frac{\Gamma \phi}{R-1}\right)^{\frac{\rho}{1-\rho}}} .
$$

Ceteris paribus, for $\lambda \Gamma \phi>R-1$, which ensures that $\frac{\partial g_{A}^{P I}}{\partial \rho}>0$, the above condition is more likely to hold for higher values of $\rho$. Under the assumption $\lambda \Gamma \phi>R-1$, the LHS of the above inequality becomes an increasing function of $\rho$, while the RHS a decreasing one. Therefore, there exists $\bar{\rho}=\bar{\rho}(\alpha, \eta, L, \lambda, \phi, R)$ such that the condition (38) holds true, $\forall \rho>\bar{\rho}$, where $\bar{\rho}$ is a solution of (38) with equality. This proves the first part of Corollary 1.1. Note that since $F(\kappa)$ is a continuous function in $\kappa$, then ceteris paribus, $\forall \rho>\bar{\rho}$, Corollary 1.1 is true at least for a range of $\kappa \in(0, \bar{\kappa}]$, where $F(\bar{\kappa})=0$.

\footnotetext{
${ }^{30}$ This is because $F(\kappa)=\kappa^{\frac{\rho+1}{1-\rho}}\left\{\left[\kappa^{-\frac{\rho}{1-\rho}}+g_{A}^{P I}\left(\kappa^{-\frac{\rho}{1-\rho}}+z \frac{R-1}{R^{2}}\right)^{\frac{\rho}{1-\rho}}\right]\left\{\kappa^{-\frac{1}{1-\rho}}-z \frac{\alpha}{R}\left[\kappa^{-\frac{\rho}{1-\rho}}+g_{A}^{P I}\left(1+z \frac{R-1}{R}\right)^{\frac{\rho}{1-\rho}}\right]\right\}-\frac{1+g_{A}^{P I}}{\kappa^{\frac{\rho+1}{1-\rho}}}\right\}$ and since $\lim _{\kappa \rightarrow \infty} \kappa^{\tilde{\rho}}=\infty$ for any $\tilde{\rho}>0$, then because the term in parentheses is finite and negative, it follows that $\lim _{\kappa \rightarrow \infty} F(\kappa)=-\infty$.
} 
Finally, in order to show that $\frac{d \kappa}{d T}>0$, apply the implicit function theorem for

$$
G(\kappa, T) \equiv G_{1}(\kappa, T) G_{2}(\kappa)-1=c>0
$$

Then, $\frac{d \kappa}{d T}=-\frac{G_{T}}{G_{\kappa}}=-\frac{\frac{\partial G_{1}(\kappa, T)}{\partial T} G_{2}(\kappa)}{\frac{\partial G_{1}(\kappa, T)}{\partial \kappa} G_{2}(\kappa)+G_{1}(\kappa, T) G_{2}^{\prime}(\kappa)}$, where given the analysis above it is straightforward that $\frac{\partial G_{1}(\kappa \kappa)}{\partial \kappa}>0$ and $G_{2}^{\prime}(\kappa)>0$.

Therefore, $\frac{\partial G_{1}(\kappa, T)}{\partial \kappa} G_{2}(\kappa)+G_{1}(\kappa, T) G_{2}^{\prime}(\kappa)>0$, and for $\frac{d \kappa}{d T}>0$, it is sufficient that $\frac{\partial G_{1}(\kappa, T)}{\partial T}<0$.

Given that $T$ is a discrete variable, $\frac{\partial G_{1}(\kappa, T)}{\partial T}<0$ holds if $\frac{G_{1}(\kappa, 2)}{G_{1}(\kappa, 3)}>\frac{G_{1}(\kappa, 3)}{G_{1}(\kappa, 4)}>$ $\frac{G_{1}(\kappa, 4)}{G_{1}(\kappa, 5)}>\ldots$, etc. From the results at the beginning of this section $G_{1}(\kappa, 2)=$ $\frac{1+g_{A}^{P I}\left(1+z \kappa \frac{R-1}{R^{2}}\right)^{\frac{\rho}{1-\rho}}}{1+g_{A}^{P I}}, G_{1}(\kappa, 3)=G_{1}(\kappa, 2) \frac{\left(1+g_{A}^{P I}\left(1+z \kappa \frac{R-1}{R^{3}}\right)^{\frac{\rho}{1-\rho}}\right)}{\left(1+g_{A}^{P I}\right)^{2}}, G_{1}(\kappa, 4)=G_{1}(\kappa, 3) \frac{\left(1+g_{A}^{P I}\left(1+z \kappa \frac{R-1}{R^{4}}\right)^{\frac{\rho}{1-\rho}}\right)}{\left(1+g_{A}^{P I}\right)^{2}}$, etc. As $\left(1+z \kappa \frac{R-1}{R^{T}}\right)^{\frac{\rho}{1-\rho}}$ is decreasing in $T$, it is clear that $\frac{G_{1}(\kappa, T-2)}{G_{1}(\kappa, T-1)}>\frac{G_{1}(\kappa, T-1)}{G_{1}(\kappa, T)}$ and $\frac{\partial G_{1}(\kappa, T)}{\partial T}<0$. Therefore given that $\rho>\bar{\rho}$, the degree of optimism, $\kappa$, that increases consumption of the generation consuming in period $\tau+T$ is higher.

\section{Proof of Corollary 1.2}

The first-best allocations maximize the PDV of aggregate consumption in the economy (or equivalently the PDV of wealth). ${ }^{31}$ The solution focuses on a steady-state growth path.

From (3), $X_{t}=\int_{0}^{A_{t}} \eta x_{t}(j) d j$, and (9), consumption in period $t$ is $C_{t}=(\phi L)^{1-\alpha} \int_{0}^{A_{t}} x_{t}^{\alpha}(j) d j-\int_{0}^{A_{t}} \eta x_{t}(j) d j+R M_{t-1}-M_{t}$. Replacing this in aggregate welfare $W_{1}=\sum_{t=1}^{\infty} \frac{1}{R^{t-1}} C_{t}$, and using the law of motion for R\&D from

$$
A_{t+1}=\lambda I_{t}^{\rho} A_{t}^{1-\rho}+A_{t}
$$

\footnotetext{
${ }^{31}$ It is assumed that there is perfect information regarding $\phi_{t} \forall t$. The solution to the deterministic equilibrium provides with a useful benchmark for the PI and the model economy.
} 
(see (6) and (7)), the social planner solves

$$
\begin{aligned}
& \max _{I_{t}, x_{t}(j), A_{t+1}}\left\{\sum _ { t = 1 } ^ { \infty } \frac { 1 } { R ^ { t - 1 } } \left[(\phi L)^{1-\alpha} \int_{0}^{A_{t}} x_{t}^{\alpha}(j) d j-\int_{0}^{A_{t}} \eta x_{t}(j) d j-I_{t}+\right.\right. \\
& \left.\left.+q_{A, t}\left(A_{t}+\lambda I_{t}^{\rho} A_{t}^{1-\rho}-A_{t+1}\right)\right]\right\},
\end{aligned}
$$

where $q_{A, t}$ is the social value of a variety in terms of final output. Given the welfare criterion, the decision regarding $M_{t}$ drops out of the aggregate welfare given the discount rate of $\frac{1}{R}, M_{0}$ is given and $\lim _{t \rightarrow \infty} \frac{1}{R^{t-1}} M_{t} \rightarrow 0$.

The FOC with respect to investment in intermediate-good varieties $\frac{1}{R^{t-1}}\left[\alpha(\bar{\phi} L)^{1-\alpha} x_{t}^{\alpha-1}(j)-\eta\right]=0, \forall j$, implies that its optimal level is constant over time and the same across varieties

$$
x^{S P}=\left(\frac{\alpha}{\eta}\right)^{\frac{1}{1-\alpha}} \phi L, \forall j .
$$

The condition for optimal R\&D investment $\frac{1}{R^{t-1}}\left[-1+q_{A, t} \rho \lambda I_{t}^{\rho-1} A_{t}^{1-\rho}\right]=0$, implies that opportunity cost of $\mathrm{R} \& \mathrm{D}$ investment within each period equals its marginal product

$$
\frac{1}{q_{A, t}}=\rho \lambda\left(\iota_{t}^{S P}\right)^{\rho-1}
$$

where $\iota_{t}^{S P} \equiv \frac{I_{t}^{S P}}{A_{t}^{S P}}$. In a steady state $\mathrm{R} \& \mathrm{D}$ growth rate is constant $g_{A, t}^{S P}=g_{A}^{S P}$. Given $(39), \iota_{t}^{S P}=\left(\frac{g_{A}^{S P}}{\lambda}\right)^{\frac{1}{\rho}}=\iota^{S P}$ is constant as well and (40) implies constant value of a variety $q_{A, t}=q_{A}$. The optimal decision on $A_{t+1}$ implies that

$$
R q_{A}=\left[(\phi L)^{1-\alpha}\left(x^{S P}\right)^{\alpha}-\eta x^{S P}\right]+q_{A}\left[1+(1-\rho) \lambda\left(\iota^{S P}\right)^{\rho}\right]
$$

where the path of $A_{t}$ ensures that the TVC condition, $\lim _{T \rightarrow \infty} \frac{q_{A}}{R^{T}} A_{T}=0$, is satisfied. For the latter it is sufficient that $g_{A}^{S P}<R-1$. The last two marginal conditions jointly require that the returns on the two assets are equal,

$$
R-1=\rho \lambda^{1 / \rho}\left(g_{A}^{S P}\right)^{\frac{\rho-1}{\rho}} \frac{\Gamma \phi}{\alpha^{\frac{1}{1-\alpha}}}+(1-\rho) g_{A}^{S P} .
$$

Using the returns' equation result back into $\frac{1}{q_{A}}=\rho \lambda^{1 / \rho} g_{A}^{S P \frac{\rho-1}{\rho}}$, it follows that 
the value of a new variety is

$$
P^{S P} \equiv q_{A}=\frac{\Gamma \phi}{\alpha^{\frac{1}{1-\alpha}}} \frac{1}{R-(1-\rho) g_{A}^{S P}-1},
$$

where $R-1>(1-\rho) g^{S P}$ holds true from the TVC condition. The latter directly contrasts with the market value of a new variety in the PI economy, which is given by its equity market valuation (23). Comparing (23) with (42),

$$
\frac{P^{S P}}{P^{P I}}=\frac{1}{\alpha^{\frac{1}{1-\alpha}}} \frac{R-1}{R-(1-\rho) g_{A}^{S P}-1} .
$$

Given that $\alpha<1, P^{S P}>P^{P I}$ for any parameter values.

\section{Proof of Corollary 1.3}

From (40), the socially optimal investment is $\iota^{S P}=\left(q_{A} \rho \lambda\right)^{\frac{1}{1-\rho}}$. Using then (39), the corresponding growth rate of $\mathrm{R} \& \mathrm{D}$ is $g_{A}^{S P}=\lambda\left(\iota^{S P}\right)^{\rho}=\lambda^{\frac{1}{1-\rho}}\left(q_{A} \rho\right)^{\frac{\rho}{1-\rho}}$. In the $\mathrm{PI}$ economy, the growth rate of $\mathrm{R} \& \mathrm{D}$ is given by (15) when $P_{t}=P^{P I}$ as $g_{A}^{P I}=$ $\lambda^{\frac{1}{1-\rho}}\left(P^{P I}\right)^{\frac{\rho}{1-\rho}}$ and the investment $\iota^{P I}=\left(P^{P I} \lambda\right)^{\frac{1}{1-\rho}}$.

This implies that there is underinvestment in $\mathrm{R} \& \mathrm{D}$ compared to the socially optimal $\left(\iota^{P I}<\iota^{S P}\right)$ and lower R\&D growth $\left(g_{A}^{P I}<g_{A}^{S P}\right)$ if $P^{P I}<q_{A} \rho$. From $(23)$ and (42), this holds if

$$
\frac{\rho q_{A}}{P^{P I}}=\frac{\rho}{\alpha^{\frac{1}{1-\alpha}}} \frac{R-1}{R-(1-\rho) g_{A}^{S P}-1}>1
$$

A sufficient condition for this is $\rho \geq \alpha^{\frac{1}{1-\alpha}}$, which is assumed to be the case in Section 2 .

If $\rho<\alpha^{\frac{1}{1-\alpha}}$, there would be a tendency toward "overinvestment" in R\&D in PI economy because of congestion externality and the optimal growth rate could be lower than in PI economy. ${ }^{32}$

\footnotetext{
${ }^{32}$ Notice that in the extreme case where $\rho \rightarrow 0$, there is always overinvestment in the PI economy, i.e., $\frac{\rho q_{A}}{P^{P I}}=0<1$ and two high R\&D growth, i.e., $\lim _{\rho \rightarrow 0} g_{A}^{S P}=0$ and $\lim _{\rho \rightarrow 0} g_{A}^{P I}=\lambda$.
} 


\section{E Proof of Proposition 2}

For the following analysis it is useful to define the "consolidating" public signal $\hat{\phi}_{t-T+k} \equiv \frac{\beta_{\tilde{\phi}}}{\beta_{\tilde{\phi}}+\beta_{\phi}} \tilde{\phi}_{t-T+k}+\frac{\beta_{\phi}}{\beta_{\tilde{\phi}}+\beta_{\phi}} \bar{\phi}=z \tilde{\phi}_{t-T+k}+(1-z) \bar{\phi}$. Then one can write $\hat{\phi}_{t-T+k}=$ $\phi_{t+k}+\varepsilon_{\hat{\phi}, t-T+k}$, where $\varepsilon_{\hat{\phi}, t} \sim N\left(0, \frac{1}{\beta_{\hat{\phi}}}\right)$ and $\beta_{\hat{\phi}} \equiv \beta_{\tilde{\phi}}+\beta_{\phi}$. This summarizes the information about productivity in $t+k$, updated based on the public signals only.

In order to derive the equilibrium equity price, the following steps are followed:

1) There is an original conjecture for the equilibrium price's function. Given the distributional assumptions and the assumed information structure, a valid guess is

$$
P_{N, t}=\Gamma\left[\sum_{k=1}^{T}\left(\mu_{k} \phi_{t+k}+\hat{\mu}_{k} \hat{\phi}_{t-T+k}\right)+\bar{\mu} \bar{\phi}\right]-\mu_{s, 1} s_{t}
$$

where $\mu_{k}, \hat{\mu}_{k}, \bar{\mu}$ and $\mu_{s, 1}$ are unknown parameters.

2) In order to derive the average moments $\bar{E}\left[P_{N, t+1}+\Gamma \phi_{t+1} \mid \Omega_{N, t}\right]$ and $\overline{\operatorname{Var}}\left[P_{N, t+1}+\Gamma \phi_{t+1} \mid \Omega_{N, t}\right]$, we forward (43) by one period and add $\pi_{t+1}=\Gamma \phi_{t+1}$.

3) Once the average moments are calculated as a function of $\mu_{k}, \hat{\mu}_{k}, \bar{\mu}$ and $\mu_{s, 1}$, they are used to substitute out the respective moments in (29). It needs to be verified that $V=\overline{\operatorname{Var}}\left[P_{N, t+1}+\Gamma \phi_{t+1} \mid \Omega_{N, t}\right]$ is constant over time and across investors.

4) Coefficients of the (29) and (43) are matched and solve for $\mu_{k}, \hat{\mu}_{k}, \bar{\mu}$ and $\mu_{s, 1}$. This step verifies the original conjecture (43).

Given (43) from the first step, note that derivation of $\bar{E}\left[P_{N, t+1}+\pi_{t+1} \mid \Omega_{N, t}\right]$ and $\overline{\operatorname{Var}}\left[P_{N, t+1}+\pi_{t+1} \mid \Omega_{N, t}\right]$ requires that one aggregates the corresponding moments across investors. This in turn requires first to derive the individual investors' expectation and variance for $\left\{\phi_{t+k}, \hat{\phi}_{t+k}, \bar{\phi}, s_{t+1}\right\}$ for any $k>0$. Inspection of $\Omega_{N, t}(i)$ implies that for $k \in\{1, . ., T\}$, the only $\hat{\phi}_{t-T+k}$ and $\nu_{t-T+k}(i)$ are informative signals about $\phi_{t+k}$. Therefore,

$$
\begin{aligned}
E\left[\phi_{t+k} \mid \Omega_{N, t}(i)\right] & =E\left[\phi_{t+k} \mid \hat{\phi}_{t-T+k}, \nu_{t-T+k}(i)\right]=\frac{\beta_{\nu}}{\beta_{\hat{\phi}}+\beta_{\nu}} \nu_{t-T+k}(i)+\frac{\beta_{\hat{\phi}}}{\beta_{\hat{\phi}}+\beta_{\nu}} \hat{\phi}_{t-T+k}, \\
\operatorname{Var}\left[\phi_{t+k} \mid \Omega_{N, t}(i)\right] & =\operatorname{Var}\left[\phi_{t+k} \mid \hat{\phi}_{t-T+k}, \nu_{t-T+k}(i)\right]=\frac{1}{\beta_{\hat{\phi}}+\beta_{\nu}}
\end{aligned}
$$

for every investor $i$. Defining $\sigma \equiv \frac{\beta_{\nu}}{\beta_{\phi}+\beta_{\tilde{\phi}}+\beta_{\nu}}=\frac{\beta_{\nu}}{\beta_{\hat{\phi}}+\beta_{\nu}}$, then rewrite $E\left[\phi_{t+k} \mid \Omega_{N, t}(i)\right]=$ $\sigma \nu_{t-T+k}(i)+(1-\sigma) \hat{\phi}_{t-T+k}$. Note that trivially $E\left[\hat{\phi}_{t+k} \mid \Omega_{N, t}(i)\right]=\hat{\phi}_{t+k}$ and 
$\operatorname{Var}\left[\hat{\phi}_{t+k} \mid \Omega_{N, t}(i)\right]=\frac{1}{\beta_{\hat{\phi}}}$.

For $k>T$ the only available information about $\phi_{t+k}$ is its prior distribution, i.e., the only available signal is $\bar{\phi}$. Therefore, $E\left[\phi_{t+k} \mid \Omega_{N, t}(i)\right]=\bar{\phi}$ and $\operatorname{Var}\left[\phi_{t+k} \mid \Omega_{N, t}(i)\right]=$ $\frac{1}{\beta_{\phi}}$. It also follows that $E\left[\hat{\phi}_{t-T+k} \mid \Omega_{N, t}(i)\right]=\bar{\phi}$ and $\operatorname{Var}\left[\phi_{t+k} \mid \Omega_{N, t}(i)\right]=\frac{1}{\beta_{\phi}}+\frac{1}{\beta_{\hat{\phi}}}=$ $\frac{\beta_{\phi}+\beta_{\hat{\phi}}}{\beta_{\phi} \beta_{\hat{\phi}}}$. Finally, it is straightforward that $E\left[\bar{\phi} \mid \Omega_{N, t}(i)\right]=\bar{\phi}$ and $E\left[s_{t+1} \mid \Omega_{N, t}(i)\right]=0$.

Using the above results regarding investors' individual expectations and $\int_{0}^{1} \nu_{t-T+k}(i) d i=\phi_{t+k}$, it holds that

$$
\begin{aligned}
& \bar{E}\left[P_{N, t+1}+\Gamma \phi_{t+1} \mid \Omega_{N, t}\right]=\Gamma\left[\sigma \phi_{t+1}+(1-\sigma) \hat{\phi}_{t+1}\right]+ \\
& +\Gamma \sum_{k=1}^{T-1}\left\{\mu_{k}\left[\sigma \phi_{t+k+1}+(1-\sigma) \hat{\phi}_{t-T+k+1}\right]+\hat{\mu}_{k} \hat{\phi}_{t-T+k+1}\right\}+\Gamma\left(\mu_{T}+\hat{\mu}_{T}+\bar{\mu}\right) \bar{\phi}
\end{aligned}
$$

and the variance is time invariant and the same across investors, i.e.,

$$
V=\operatorname{Var}\left[P_{N, t+1}+\Gamma \phi_{t+1} \mid \Omega_{N, t}(i)\right]=\Gamma^{2}\left(\frac{1}{\beta_{\hat{\phi}}+\beta_{\nu}}+\sum_{k=1}^{T-1} \frac{\mu_{k}^{2}}{\beta_{\hat{\phi}}+\beta_{\nu}}+\frac{\mu_{T}^{2}}{\beta_{\phi}}+\frac{\hat{\mu}_{T}^{2}\left(\beta_{\phi}+\beta_{\hat{\phi}}\right)}{\beta_{\phi} \beta_{\hat{\phi}}}+\frac{\mu_{s, 1}^{2}}{\beta_{s}}\right)
$$

Replacing (44) and (45) in (28) one can equate the coefficients with (43). Doing so, $\mu_{1}=\frac{\sigma}{R}$ and $\mu_{k}=\mu_{k-1} \frac{\sigma}{R}$ for $k \in\{2, \ldots, T\}$. Solving this iteratively gives $\mu_{k}=$ $\frac{\sigma^{k}}{R^{k}}$. Also, $\hat{\mu}_{1}=\frac{1-\sigma}{R}$ and $\hat{\mu}_{k}=\frac{\mu_{k-1}(1-\sigma)+\hat{\mu}_{k-1}}{R}$, which gives $\hat{\mu}_{k}=\frac{1-\sigma^{k}}{R^{k}}$ for $k \in$ $\{2, \ldots, T\}$. Given these, we can find $\bar{\mu}$ from $\frac{\mu_{T}+\hat{\mu}_{T}+\bar{\mu}}{R}=\bar{\mu}$ as $\bar{\mu}=\frac{1}{R^{T}(R-1)}$. The last coefficient $\mu_{s, 1}=\frac{\gamma V}{R}=\frac{\gamma \Gamma^{2}\left(\frac{1}{\beta_{\hat{\phi}}+\beta_{\nu}}+\sum_{k=1}^{T-1}\left(\frac{\sigma^{k}}{R^{k}}\right)^{2} \frac{1}{\beta_{\hat{\phi}}+\beta_{\nu}}+\left(\frac{\sigma^{T}}{R^{T}}\right)^{2} \frac{1}{\beta_{\phi}}+\left(\frac{1-\sigma^{T}}{R^{T}}\right)^{2} \frac{\beta_{\phi}+\beta_{\hat{\phi}}}{\beta_{\phi} \beta_{\hat{\phi}}}+\mu_{s, 1}^{2} \frac{1}{\beta_{s}}\right)}{R}$. The solution to this quadratic equation solves for $\mu_{s, 1}$ and determines $V=\frac{R \mu_{s, 1}}{\gamma} \cdot{ }^{33}$ The solution for these coefficients confirms that the initial equilibrium price function guess was valid.

Finally replacing $\mu_{k}, \hat{\mu}_{k}$ for $k \in\{1, . ., T\}, \hat{\mu}$ and $\mu_{s, 1}$ in (43) and using the definition of $\hat{\phi}_{t-T+k}$ gives $(29)$.

\footnotetext{
${ }^{33}$ To ensure a well-defined solution for $\mu_{s, 1}$ and $V$, a sufficient condition is $\left(\frac{R}{\gamma \Gamma^{2}}\right)^{2} \geq 4 \frac{1}{\beta_{s}}\left[\frac{1}{\beta_{\hat{\phi}}+\beta_{\nu}}+\sum_{k=1}^{T-1}\left(\frac{\sigma^{k}}{R^{k}}\right)^{2} \frac{1}{\beta_{\hat{\phi}}+\beta_{\nu}}+\left(\frac{\sigma^{T}}{R^{T}}\right)^{2} \frac{1}{\beta_{\phi}}+\left(\frac{1-\sigma^{T}}{R^{T}}\right)^{2} \frac{\beta_{\phi}+\beta_{\hat{\phi}}}{\beta_{\phi} \beta_{\hat{\phi}}}\right]$. When this is satis-
} fied as equality, it implies a minimum real bound for the variance: $V \geq \frac{R^{2} \beta_{s}}{2 \gamma^{2} \Gamma^{2}}$. 


\section{F Infinite-horizon model equilibrium equity price}

It is conjectured that the equilibrium equity price takes the form (33). Defining the "consolidating" public signal as in Appendix E as $\hat{\phi}_{t-T+1} \equiv z \tilde{\phi}_{t-T+k}+(1-z) \bar{\phi}=$ $\phi_{t+k}+\varepsilon_{\hat{\phi}, t-T+k}$, where $\varepsilon_{\hat{\phi}, t} \sim N\left(0, \frac{1}{\beta_{\hat{\phi}}}\right)$ and $\beta_{\hat{\phi}} \equiv \beta_{\tilde{\phi}}+\beta_{\phi}$, the conjectured equity price (33) can be expressed in matrix form as

$$
P_{t}=\Gamma\left[\mathcal{M}_{1}^{\prime} \Phi_{t}+\hat{\mathcal{M}}^{\prime} \hat{\Phi}_{t}+\bar{\mu} \bar{\phi}\right]
$$

where $\Phi_{t}=\left(\phi_{t+1}, . ., \phi_{t+T}, \frac{s_{t-T+1}}{\Gamma}, . ., \frac{s_{t}}{\Gamma}\right)^{\prime}$ contains the variables that affect equity prices and are unobservable by consumers. The vector $\hat{\Phi}_{t}=\left(\hat{\phi}_{t-T+1}, \ldots, \hat{\phi}_{t}\right)^{\prime}$ contains the consolidating public signals. The independent presence of $\bar{\phi}$ is used to facilitate the numerical solution and does not affect the results, apart from making the price more explicitly a function of potential innovations in future productivity. Finally, the vectors of coefficients, $\bar{\mu}, \mathcal{M}_{1}=\left(\mu_{1}, . ., \mu_{T},-\mu_{s, 1}, . .,-\mu_{s, T}\right)^{\prime}$ and $\hat{\mathcal{M}}=\left(\hat{\mu}_{1}, . ., \hat{\mu}_{T}\right)^{\prime}$, depend on the parameters that govern the distributions of the various shocks and signals.

As for the model with naive expectations, the solution method starts from (28), assuming that the price equation is in the form of (46).

Conditional only on the public signals, the "prior" distribution of $\Phi_{t}(2 T \times 1)$ is:

$$
\begin{aligned}
& \Phi_{t} \sim \mathcal{N}\left(\hat{\Phi}_{0, t}, \Sigma_{\Phi}\right) \\
& \hat{\Phi}_{0, t}=\left(\hat{\phi}_{t-T+1}, \ldots, \hat{\phi}_{t}, 0, . ., 0\right)^{\prime}
\end{aligned}
$$

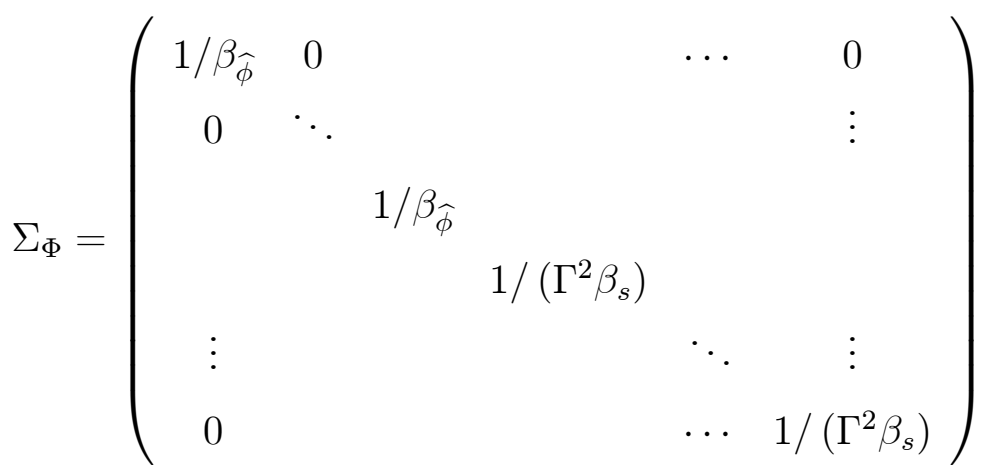


The price signals for $k=[0, T-1]$ are defined as:

$$
\tilde{P}_{t-k}=P_{t-k}-\Gamma \bar{\mu} \bar{\phi}-\Gamma \hat{\mathcal{M}}^{\prime} \hat{\Phi}_{t}-\Gamma \sum_{l=1}^{k}\left(\mu_{l} \phi_{t-k+l}-\mu_{s, l} \frac{s_{t-T-k+l}}{\Gamma}\right) .
$$

The vector of observables for investor $i$ trading in period $t$ is defined as $\Lambda_{t}(i)=\left(\widetilde{P}_{t}, \ldots, \widetilde{P}_{t-T+1}, v_{t-T+1}(i), \ldots, v_{t}(i)\right)^{\prime}, \Lambda_{t}(i)$ is $(2 T \times 1)$. Then

$$
\begin{aligned}
& \Lambda_{t}(i)= \Gamma \mathcal{M} \Phi_{t}+\varepsilon_{t} ; \\
& \varepsilon_{t}=\left(0, \ldots, 0, \varepsilon_{t}(i), \ldots, \varepsilon_{t-T+1}(i)\right)^{\prime} \\
& \mathcal{M}=\left(\begin{array}{cccccccc}
\mu_{1} & \ldots & \mu_{T-1} & \mu_{T} & -\mu_{s, 1} & \ldots & -\mu_{s, T-1} & -\mu_{s, T} \\
\mu_{2} & \ldots & \mu_{T} & 0 & -\mu_{s, 2} & \ldots & -\mu_{s, T} & 0 \\
\vdots & \ddots & 0 & 0 & \vdots & \ddots & 0 & 0 \\
\mu_{T} & \ldots & 0 & 0 & -\mu_{s, T} & \ldots & 0 & 0 \\
1 / \Gamma & \ldots & 0 & 0 & 0 & \ldots & 0 & 0 \\
\vdots & \ddots & 0 & 0 & \vdots & \ddots & 0 & 0 \\
0 & 0 & 1 / \Gamma & 0 & 0 & 0 & 0 & 0 \\
0 & 0 & 0 & 1 / \Gamma & 0 & 0 & 0 & 0
\end{array}\right)
\end{aligned}
$$

This implies that

$$
\begin{aligned}
\Lambda_{t}(i) \mid \Phi_{t} \sim \mathcal{N}\left(\Gamma \mathcal{M} \Phi_{t}, \Sigma_{\Lambda}\right) ; \\
\Sigma_{\Lambda}=\left(\begin{array}{cccccc}
0 & \cdots & 0 & 0 & \cdots & 0 \\
\vdots & \ddots & \vdots & \vdots & \ddots & \vdots \\
0 & \cdots & 0 & 0 & \cdots & 0 \\
0 & \cdots & 0 & 1 / \beta_{v} & \cdots & 0 \\
\vdots & \ddots & \vdots & \vdots & \ddots & \vdots \\
0 & \cdots & 0 & 0 & \cdots & 1 / \beta_{v}
\end{array}\right)
\end{aligned}
$$

The updated distribution of the unobservables, conditional on the observables 
for each of the consumer $i$, is found with the use of the projection theorem:

$$
\begin{aligned}
E\left[\Phi_{t} \mid \Lambda_{t}(i)\right] & =\hat{\Phi}_{0, t}+\Gamma \Sigma_{\Phi} \mathcal{M}^{\prime}\left(\Gamma^{2} \mathcal{M} \Sigma_{\Phi} \mathcal{M}^{\prime}+\Sigma_{\Lambda}\right)^{-1}\left(\Lambda_{t}(i)-\Gamma \mathcal{M} \hat{\Phi}_{0, t}\right) \\
\operatorname{Var}\left[\Phi_{t} \mid \Lambda_{t}(i)\right] & =\Sigma_{\Phi}-\Gamma^{2} \Sigma_{\Phi} \mathcal{M}^{\prime}\left(\Gamma^{2} \mathcal{M} \Sigma_{\Phi} \mathcal{M}^{\prime}+\Sigma_{\Lambda}\right)^{-1} \mathcal{M} \Sigma_{\Phi} \equiv V_{\Phi}
\end{aligned}
$$

where $V_{\Phi}$ indicates that the conditional variance of unobservables, which is constant over time and the same from the point of view of every consumer. Aggregating over all rational investors, provides with the average expectations of the unobservables:

$$
\bar{E}\left[\Phi_{t} \mid \Lambda_{t}\right]=(I-Q \mathcal{M}) \hat{\Phi}_{0, t}+Q \mathcal{M} \Phi_{t}
$$

where $Q \equiv \Gamma^{2} \Sigma_{\Phi} \mathcal{M}^{\prime}\left(\Gamma^{2} \mathcal{M} \Sigma_{\Phi} \mathcal{M}^{\prime}+\Sigma_{\Lambda}\right)^{-1}$ and $I$ is the $(2 T \times 2 T)$ identity matrix. Using this:

$\bar{E}\left[P_{t+1}+\Gamma \phi_{t+1} \mid \Omega_{t}\right]=\Gamma\left(\left(\mu_{T}+\hat{\mu}_{T}+\bar{\mu}\right) \bar{\phi}+\left(\mathcal{M}_{2}^{\prime}(I-Q \mathcal{M})+\hat{\mathcal{M}}_{2}^{\prime}\right) \hat{\Phi}_{0, t}+\mathcal{M}_{2}^{\prime} Q \mathcal{M} \Phi_{t}\right)$

$V \equiv \operatorname{Var}\left[P_{t+1}+\Gamma \phi_{t+1} \mid \Omega_{t}\right]=\Gamma^{2}\left[\mathcal{M}_{2}^{\prime} V_{\Phi} \mathcal{M}_{2}+\mu_{T}^{2} \frac{1}{\beta_{\phi}}+\hat{\mu}_{T}^{2} \frac{\beta_{\hat{\phi}}-\beta_{\phi}}{\beta_{\hat{\phi}} \beta_{\phi}}+\frac{\mu_{s, T}^{2}}{\Gamma^{2}} \frac{1}{\beta_{s}}\right]$

where $\mathcal{M}_{2}^{\prime}=\left(1, \mu_{1}, . ., \mu_{T-1}, 0,-\mu_{s, 1}, . .,-\mu_{s, T-1}\right)$ and $\hat{\mathcal{M}}_{2}^{\prime}=\left(0, \hat{\mu}_{1}, . ., \hat{\mu}_{T-1}, 0,0, \ldots, 0\right)$.

The variance is verified to be constant over time and homogeneous across consumers. It depends on the coefficients and precision of shocks. The average expectation is linear in future productivity, historical noise trading and public signals, while $s_{t}$ enters into price equation from (28) directly. Therefore, the prices take the form of the conjectured price equation and the vectors of coefficients $\mathcal{M}_{1}$ and $\hat{\mathcal{M}}$ can be recovered numerically by replacing the above results into (28) and equating coefficients with (46). Using then the definition of $\hat{\phi}_{t-T+1}$ implies that equilibrium equity price takes the form (33).

\section{G Proof of Proposition 3}

Assume that $\varepsilon_{\tilde{\phi}_{\tau}}=\kappa_{\tau} \phi$ and $\varepsilon_{\tilde{\phi}_{\tau+1}}=\kappa_{\tau} \kappa_{\tau+1} \phi$. For the proof of the result, it is sufficient that there exist $\kappa_{\tau}>0$ and $\kappa_{\tau+1}>0$ such that $C_{t} \geq C_{t}^{P I}$ for every $t$. 
Using (21) and (23), consumption in PI economy is always proportional to the level of technology $C_{t}^{P I}=A_{t-1}^{P I} \frac{R}{\alpha} \Gamma \phi$. Using (15), the growth rate of R\&D is constant $g_{A}^{P I}=\lambda^{\frac{1}{1-\rho}}\left(P^{P I}\right)^{\frac{\rho}{1-\rho}}$, where $P^{P I}$ is given by $(23)$.

Similarly to Corollary 1.1, it is easy to show that equilibrium allocations in the model and the PI economy are identical before period $\tau$, i.e., $C_{t}=C_{t}^{P I}$, for $t<\tau$, while $C_{\tau+k}=\frac{R}{\alpha} \Gamma \phi A_{\tau+k-1}>\frac{R}{\alpha} \Gamma \phi A_{\tau+k-1}^{P I}=C_{\tau+k}^{P I}$ for $k>3$, due to the temporarily higher R\&D growth in the model economy.

In the model economy equity prices will be higher for three consecutive periods and from (33) are given by

$$
\begin{aligned}
P_{\tau} & =\frac{\Gamma \phi}{R-1}+z \hat{\mu}_{2} \Gamma \kappa_{\tau} \phi>P^{P I}, \\
P_{\tau+1} & =\frac{\Gamma \phi}{R-1}+z \hat{\mu}_{1} \Gamma \kappa_{\tau} \phi+z \hat{\mu}_{2} \Gamma \kappa_{\tau} \kappa_{\tau+1} \phi>P^{P I}, \\
P_{\tau+2} & =\frac{\Gamma \phi}{R-1}+z \hat{\mu}_{1} \Gamma \kappa_{\tau} \kappa_{\tau+1} \phi>P^{P I} .
\end{aligned}
$$

Using (15), the growth rate of technology will also be higher for three consecutive periods and can be expressed as

$$
\begin{aligned}
g_{A, \tau} & =g_{A}^{P I}\left(1+(R-1) z \hat{\mu}_{2} \kappa_{\tau}\right)^{\frac{\rho}{1-\rho}}>g_{A}^{P I} \\
g_{A, \tau+1} & =g_{A}^{P I}\left(1+(R-1) \kappa_{\tau} z\left(\hat{\mu}_{1}+\hat{\mu}_{2} \kappa_{\tau+1}\right)\right)^{\frac{\rho}{1-\rho}}>g_{A}^{P I} \\
g_{A, \tau+2} & =g_{A}^{P I}\left(1+(R-1) z \hat{\mu}_{1} \kappa_{\tau} \kappa_{\tau+1}\right)^{\frac{\rho}{1-\rho}}>g_{A}^{P I} .
\end{aligned}
$$

Consumption in period $\tau$ is given by $C_{\tau}=z \hat{\mu}_{2} \kappa_{\tau} \Gamma \phi A_{\tau}^{P I}+A_{\tau-1}^{P I} \frac{R}{\alpha} \Gamma \phi>C_{t}^{P I}$, whenever $\kappa_{\tau}>0$ because of higher equity prices they receive. Hence, one needs to find conditions that make the remaining three generations (consumers in $\tau+1, \tau+2$ and $\tau+3)$ at least as well off as the PI economy.

Consumption in $\tau+1$ is

$$
C_{\tau+1}=z \kappa_{\tau} \phi\left(\hat{\mu}_{1}+\hat{\mu}_{2} \kappa_{\tau+1}-R \hat{\mu}_{2}\right) \Gamma A_{\tau}^{P I}\left(1+g_{A, \tau}\right)+A_{\tau}^{P I} \frac{R}{\alpha} \Gamma \phi
$$

Therefore, $C_{\tau+1} \geq C_{\tau+1}^{P I}$ iff $\kappa_{\tau+1} \geq \frac{R \hat{\mu}_{2}-\hat{\mu}_{1}}{\hat{\mu}_{2}}>0 .^{34}$ Because is sufficient if this

\footnotetext{
${ }^{34}$ Because of higher order beliefs (as in Section 4.1) and the additional information about $\phi_{t+2}$ that is revealed by equity prices in $t+1$, it holds that $\hat{\mu}_{2}>\frac{\hat{\mu}_{1}}{R}$. Thus, the weight on the public
} 
condition is satisfied with an equality, then

$$
\kappa_{\tau+1}=\frac{R \hat{\mu}_{2}-\hat{\mu}_{1}}{\hat{\mu}_{2}}
$$

Consumption in period $\tau+2$ is given by

$C_{\tau+2}=-\frac{R \hat{\mu}_{1} \hat{\mu}_{2}+\left(R \hat{\mu}_{2}-\hat{\mu}_{1}\right)^{2}}{\hat{\mu}_{2}} z \kappa_{\tau} \Gamma \phi A_{\tau}^{P I}\left(1+g_{A, \tau}\right)\left(1+g_{A, \tau+1}\right)+R \frac{\Gamma \phi}{\alpha} A_{\tau}^{P I}\left(1+g_{A, \tau}\right)$,

and $C_{t+2} \geq C_{t+2}^{P I}$ if there is $\kappa_{t}>0$ such that $F\left(\kappa_{t}\right) \geq 0$, where

$$
F\left(\kappa_{t}\right) \equiv\left(g_{A, t}-g_{A}^{P I}\right)-\frac{\alpha\left[R \hat{\mu}_{1} \hat{\mu}_{2}+\left(R \hat{\mu}_{2}-\hat{\mu}_{1}\right)^{2}\right]}{R \hat{\mu}_{2}} z \kappa_{t}\left(1+g_{A, \tau}\right)\left(1+g_{A, \tau+1}\right) .
$$

Note that $F(0)=0$. It is sufficient for the purpose of this proof that one examines whether the above condition holds true in the neighborhood of $\kappa_{t}=0$, i.e., employing the first-order Taylor approximation: $F\left(\kappa_{t}\right) \simeq F^{\prime}(0) \kappa_{t}$. The sufficient condition boils down to the condition for $F^{\prime}(0)>0$. In order to simplify the analysis define,

$$
\begin{aligned}
g_{A, \tau} & =g_{A}^{P I}\left(1+g_{0} \kappa_{\tau}\right)^{\frac{\rho}{1-\rho}} ; g_{0} \equiv(R-1) z \hat{\mu}_{2} \\
g_{A, \tau+1} & =g_{A}^{P I}\left(1+g_{1} \kappa_{\tau}\right)^{\frac{\rho}{1-\rho}} ; g_{1} \equiv(R-1) R z \hat{\mu}_{2} \\
g_{A, \tau+2} & =g_{A}^{P I}\left(1+g_{2} \kappa_{\tau}\right)^{\frac{\rho}{1-\rho}} ; g_{2} \equiv(R-1) z \frac{\hat{\mu}_{1}\left(R \hat{\mu}_{2}-\hat{\mu}_{1}\right)}{\hat{\mu}_{2}} .
\end{aligned}
$$

and

$$
\begin{aligned}
F\left(\kappa_{\tau}\right) & =g_{A}^{P I}\left[\left(1+g_{0} \kappa_{\tau}\right)^{\frac{\rho}{1-\rho}}-1\right] \\
& -g_{3} \kappa_{\tau}\left[1+g_{A}^{P I}\left(1+g_{1} \kappa_{\tau}\right)^{\frac{\rho}{1-\rho}}\right]\left[1+g_{A}^{P I}\left(1+g_{2} \kappa_{\tau}\right)^{\frac{\rho}{1-\rho}}\right] \\
; g_{3} & \equiv \frac{z \alpha\left[R \hat{\mu}_{1} \hat{\mu}_{2}+\left(R \hat{\mu}_{2}-\hat{\mu}_{1}\right)^{2}\right]}{R \hat{\mu}_{2}} .
\end{aligned}
$$

signal (adjusted for $\mathrm{R}$ ) must decrease over time. 
Therefore,

$$
\begin{aligned}
F^{\prime}\left(\kappa_{t}\right) & =g_{A}^{P I} \frac{\rho}{1-\rho}\left(1+g_{0} \kappa_{\tau}\right)^{\frac{\rho}{1-\rho}-1} g_{0} \\
& -g_{3}\left[1+g_{A}^{P I}\left(1+g_{1} \kappa_{\tau}\right)^{\frac{\rho}{1-\rho}}\right]\left[1+g_{A}^{P I}\left(1+g_{2} \kappa_{\tau}\right)^{\frac{\rho}{1-\rho}}\right] \\
& -g_{3} \kappa_{\tau} g_{A}^{P I} \frac{\rho}{1-\rho}\left(1+g_{1} \kappa_{\tau}\right)^{\frac{\rho}{1-\rho}-1} g_{1}\left[1+g_{A}^{P I}\left(1+g_{2} \kappa_{\tau}\right)^{\frac{\rho}{1-\rho}}\right] \\
& -g_{3} \kappa_{\tau} g_{A}^{P I} \frac{\rho}{1-\rho}\left(1+g_{2} \kappa_{\tau}\right)^{\frac{\rho}{1-\rho}-1} g_{2}\left[1+g_{A}^{P I}\left(1+g_{1} \kappa_{\tau}\right)^{\frac{\rho}{1-\rho}}\right]
\end{aligned}
$$

When $\kappa_{\tau}=0, F^{\prime}(0)=g_{A}^{P I} \frac{\rho}{1-\rho}-g_{3}\left(1+g_{A}^{P I}\right)^{2}$. Therefore, the sufficient condition for $F^{\prime}(0)>0$ is that parameters satisfy

$$
\frac{g_{A}^{P I}}{\left(1+g_{A}^{P I}\right)^{2}} \frac{\rho}{1-\rho}>g_{3}
$$

The proof that there are parameters that ensure the existence of $\kappa_{\tau}>0$ such that $C_{\tau+3}>C_{\tau+3}^{P I}$ follows similar arguments. Consumption in period $\tau+3$ is

$$
\begin{aligned}
C_{t+\tau} & =-R \Gamma \phi \kappa_{\tau} \frac{z \hat{\mu}_{1}\left(R \hat{\mu}_{2}-\hat{\mu}_{1}\right)}{\hat{\mu}_{2}} A_{t}^{P I}\left(1+g_{A, \tau}\right)\left(1+g_{A, \tau+1}\right)\left(1+g_{A, \tau+2}\right) \\
& +A_{t}^{P I}\left(1+g_{A, \tau}\right)\left(1+g_{A, \tau+1}\right) \frac{R}{\alpha} \Gamma \phi
\end{aligned}
$$

and $C_{t+3}>C_{t+3}^{P I}$ if there exist $\kappa_{\tau}>0$, such that $G\left(\kappa_{\tau}\right) \geq 0$, where

$$
\begin{aligned}
G\left(\kappa_{\tau}\right) & \equiv\left[\left(1+g_{A, \tau}\right)\left(1+g_{A, \tau+1}\right)-\left(1+g_{A}^{P I}\right)^{2}\right] \\
& -\alpha \frac{z \hat{\mu}_{1}\left(R \hat{\mu}_{2}-\hat{\mu}_{1}\right)}{\hat{\mu}_{2}} \kappa_{\tau}\left(1+g_{A, \tau}\right)\left(1+g_{A, \tau+1}\right)\left(1+g_{A, \tau+2}\right) .
\end{aligned}
$$

Hence, $G\left(\kappa_{t}\right)=$

$$
\begin{aligned}
& {\left[1+g_{A}^{P I}\left(1+g_{0} \kappa_{\tau}\right)^{\frac{\rho}{1-\rho}}\right]\left[1+g_{A}^{P I}\left(1+g_{1} \kappa_{\tau}\right)^{\frac{\rho}{1-\rho}}\right]-\left(1+g_{A}^{P I}\right)^{2}} \\
& -g_{4} \kappa_{\tau}\left[1+g_{A}^{P I}\left(1+g_{0} \kappa_{\tau}\right)^{\frac{\rho}{1-\rho}}\right]\left[1+g_{A}^{P I}\left(1+g_{1} \kappa_{\tau}\right)^{\frac{\rho}{1-\rho}}\right]\left[1+g_{A}^{P I}\left(1+g_{2} \kappa_{\tau}\right)^{\frac{\rho}{1-\rho}}\right],
\end{aligned}
$$


where $g_{4} \equiv \alpha \frac{z \hat{\mu}_{1}\left(R \hat{\mu}_{2}-\hat{\mu}_{1}\right)}{\hat{\mu}_{2}}$. Note that $G(0)=0$, and $G^{\prime}\left(\kappa_{\tau}\right)=$

$$
\begin{aligned}
& g_{A}^{P I} \frac{\rho}{1-\rho}\left(1+g_{0} \kappa_{\tau}\right)^{\frac{\rho}{1-\rho}-1} g_{0}\left[1+g_{A}^{P I}\left(1+g_{1} \kappa_{\tau}\right)^{\frac{\rho}{1-\rho}}\right] \\
& +g_{A}^{P I} \frac{\rho}{1-\rho}\left(1+g_{1} \kappa_{\tau}\right)^{\frac{\rho}{1-\rho}-1} g_{1}\left[1+g_{A}^{P I}\left(1+g_{0} \kappa_{\tau}\right)^{\frac{\rho}{1-\rho}}\right] \\
& -g_{4}\left[1+g_{A}^{P I}\left(1+g_{0} \kappa_{\tau}\right)^{\frac{\rho}{1-\rho}}\right]\left[1+g_{A}^{P I}\left(1+g_{1} \kappa_{\tau}\right)^{\frac{\rho}{1-\rho}}\right]\left[1+g_{A}^{P I}\left(1+g_{2} \kappa_{\tau}\right)^{\frac{\rho}{1-\rho}}\right] \\
& -g_{4} \kappa_{\tau} \frac{\rho}{1-\rho}\left(1+g_{0} \kappa_{\tau}\right)^{\frac{\rho}{1-\rho}-1} g_{0}\left[1+g_{A}^{P I}\left(1+g_{1} \kappa_{\tau}\right)^{\frac{\rho}{1-\rho}}\right]\left[1+g_{A}^{P I}\left(1+g_{2} \kappa_{\tau}\right)^{\frac{\rho}{1-\rho}}\right] \\
& -g_{4} \kappa_{\tau} \frac{\rho}{1-\rho}\left(1+g_{1} \kappa_{\tau}\right)^{\frac{\rho}{1-\rho}-1} g_{1}\left[1+g_{A}^{P I}\left(1+g_{0} \kappa_{\tau}\right)^{\frac{\rho}{1-\rho}}\right]\left[1+g_{A}^{P I}\left(1+g_{2} \kappa_{\tau}\right)^{\frac{\rho}{1-\rho}}\right] \\
& -g_{4} \kappa_{\tau} \frac{\rho}{1-\rho}\left(1+g_{2} \kappa_{\tau}\right)^{\frac{\rho}{1-\rho}-1} g_{2}\left[1+g_{A}^{P I}\left(1+g_{1} \kappa_{\tau}\right)^{\frac{\rho}{1-\rho}}\right]\left[1+g_{A}^{P I}\left(1+g_{0} \kappa_{\tau}\right)^{\frac{\rho}{1-\rho}}\right] .
\end{aligned}
$$

When $\kappa_{\tau}=0, G^{\prime}(0)=g_{A}^{P I} \frac{\rho}{1-\rho}\left(1+g_{A}^{P I}\right)\left(g_{0}+g_{1}\right)-g_{4}\left(1+g_{A}^{P I}\right)^{3}$. The sufficient condition for $G\left(\kappa_{\tau}\right)>0$ for the existence of a sufficiently small $\kappa_{t}>0$ is

$$
\frac{g_{A}^{P I}}{\left(1+g_{A}^{P I}\right)^{2}} \frac{\rho}{1-\rho}>\frac{g_{4}}{g_{0}+g_{1}} .
$$

To summarize, by (48) and (49), the sufficient condition for the existence of a small strictly positive $\kappa_{\tau}$ that provides $C_{t} \geq C_{t}^{P I}$, for any $t$, is

$$
\frac{g_{A}^{P I}}{\left(1+g_{A}^{P I}\right)^{2}} \frac{\rho}{1-\rho}>\min \left\{\frac{g_{4}}{g_{0}+g_{1}}, g_{3}\right\} \text {. }
$$

This condition is likely to be satisfied for sufficiently low levels of congestion, i.e., high $\rho$.

\section{References}

Allen, F., S. Morris, And H. S. Shin (2006): "Beauty Contests and Iterated Expectations in Asset Markets," Review of Financial Studies, 19, 719-752.

Bacchetta, P., and E. V. Wincoop (2007): "Higher Order Expectations in Asset Pricing," unpublished.

Baker, M., J. C. Stein, and J. Wurgler (2003): "When Does the Market Matter? Stock Prices and the Investment of Equity-Dependent Firms," Quarterly 
Journal of Economics, 118(3), 969-1005.

Barro, R. (1990): "The Stock Market and Investment," The Review of Financial Studies, 3, 115-131.

Blanchard, O., C. Rhee, and L. H. Summers (1993): "The Stock Market, Profit and Investment," The Quarterly Journal of Economics, 108(1), 115-36.

Caballero, R., E. Farhi, and M. Hammour (2006): "Speculative Growth: Hints from the U.S. Economy," American Economic Review, 96(4), 1159-1192.

Carlin, W., and C. Mayer (2003): "Finance, Investment and Growth," Journal of Financial Economics, 69(1), 191-226.

Chan, L. K. C., N. Jegadeesh, and J. Lakonishok (1996): "Momentum Strategies," The Journal of Finance, 51(5), 1681-1713.

Comin, D., And M. Gertler (2006): "Medium Term Business Cycles," American Economic Review, 96(3), 523-551.

Cutler, D. M., J. M. Poterba, and L. H. Summers (1991): "Speculative Dynamics," Review of Economic Studies, 58(3), 529-546.

Demarzo, P. M., R. Kaniel, and I. Kremer (2007): "Technological Innovation and Real Investment Booms and Busts," Journal of Financial Economics, 85, $735-754$.

Evans, G. W., S. Honkapohja, and P. M. Romer (1998): "Growth Cycles," The American Economic Review, 88(3), 221-235.

Farhi, E., and S. Panageas (2007): “The Real Effects of Stock Market Mispricing at the Aggregate: Theory and Empirical Evidence," unpublished.

Gilchrist, S., C. P. Himmelberg, and G. Huberman (2005): "Do Stock Price Bubbles Influence Corporate Investment?," Journal of Monetary Economics, 52, 805-827. 
Griliches, Z. (1992): "The Search for R\&D Spillovers," Scandinavian Journal of Economics, 94(0), S29-S47.

Griliches, Z., B. H. Hall, and A. Pakes (1991): "R\&D, Patents and Market Value Revisited: Is There A Second (Technological Opportunity) Factor?," Journal of Economics of Innovation and New Technology, 1, 183-201.

Grossman, G. M., and E. Helpman (1991): "Quality Ladders and Product Cycles," Quarterly Journal of Economics, 106(2), 557-586.

Grossman, S. J., and J. E. Stiglitz (1980): "On the Impossibility of Informationally Efficient Markets," American Economic Review, 70(3), 393-408.

Holmes, T. J., And J. A. Schmitz JR. (1990): "A Theory of Entrepreneurship and Its Application to the Study of Business Transfers," Journal of Political Economy, 98(2), 265-294.

Ilg, R. E., And S. E. Haugen (2000): "Earnings and Employment Trends in the 1990s," Discussion paper, Bureau of Labour Statistics, Monthly Labor Review, March.

Jegadeesh, N., and S. Titman (1993): "Returns to Buying Winners and Selling Losers: Implications for Stock Market Efficiency," The Journal of Finance, 48, 65-91.

Jermann, U., And V. Quadrini (2007): "Stock Market Boom and the Productivity Gains of the 1990s," Journal of Monetary Economics, 54(2), 413-432.

Jones, C. I. (1995): "R\&D-Based Models of Economic Growth," The Journal of Political Economy, 103(4), 759-784.

Jorgenson, D. W., M. S. Ho, and K. J. Stiroh (2005): Information Technology and the American Growth Resurgence. The MIT Press, Cambridge, Massachusets.

Jovanovic, B., And B. Szentes (2007): "On the Return to Venture Capital," NBER Working Paper No. W12874. 
Kortum, S., And J. Lerner (2000): "Assessing the Contribution of Venture Capital to Innovation," RAND Journal of Economics, 31, 674-692.

Lee, C., A. Shleifer, and R. H. Thaler (1991): "Investor Sentiment and the Closed End Fund Puzzle," The Journal of Finance, 46, 75-110.

Menkhoff, L. (1998): "The Noise Trading Approach-A Questionnaire Evidence from Foreign Exchange," Journal of International Money and Finance, 17, 547564.

Morck, R., A. Shleifer, And R. W. Vishny (1990): "The Stock Market and Investments: Is the Market a Sideshow?," Brookings Papers on Economic Activity, $2,157-215$.

Murphy, K. J. (2002): "Explaining executive compensation: managerial power vs. the perceived cost of stock-options," University of Chicago Law Review.

PAkes, A. (1985): "On Patents, R\&D and the Stock Market Rate of Return," Journal of Political Economy, 93(2), 390-409.

Pastor, L., And P. Veronesi (2006): "Was there a Nasdaq bubble in late 1990s?," Journal of Financial Economics, 81, 61-100.

(2008): "Technological Revolutions and Stock Prices," forthcoming in American Economic Review.

Polk, C. K., And P. Sapienza (2008): “The Stock Market and Corporate Investment: A Test of Catering Theory," forthcoming in Review of Financial Studies.

Romer, P. M. (1990): "Endogenous Technological Change," Journal of Political Economy, 98(5), S71-102.

Shiller, R. J. (2000): Irrational Exuberance. Princeton University Press, Princeton, NJ.

Stein, J. C. (1996): "Rational capital budgeting in an irrational world," Journal of Business, 69, 429-455. 
Swaminathan, B. (1991): "Time-varying Expected Small Firm Returns and Closed-end Fund Discounts," Review of Financial Studies, 9, 845-888.

Tinn, K. (2008): "Technology adoption with exit in imperfectly informed equity markets," unpublished.

Tirole, J. (1985): “Asset Bubbles and Overlapping Generations," Econometrica, 53(6), 1499-1528.

Ventura, J. (2006): "Economic Growth With Bubbles," UPF working Paper No 848.

Vourvachaki, E. (2006): "Information and Communication Technologies in a Multi-Sector Endogenous Growth Model," CEP Discussion Paper No 750. 
Individual researchers, as well as the on-line and printed versions of the CERGE-EI Working Papers (including their dissemination) were supported from the following institutional grants:

- Economic Aspects of EU and EMU Entry [Ekonomické aspekty vstupu do Evropské unie a Evropské měnové unie], No. AVOZ70850503, (2005-2010);

- Economic Impact of European Integration on the Czech Republic [Ekonomické dopady evropské integrace na ČR], No. MSM0021620846, (2005-2011);

Specific research support and/or other grants the researchers/publications benefited from are acknowledged at the beginning of the Paper.

(c) Katrin Tinn and Evangelia Vourvachaki, 2009

All rights reserved. No part of this publication may be reproduced, stored in a retrieval system or transmitted in any form or by any means, electronic, mechanical or photocopying, recording, or otherwise without the prior permission of the publisher.

Published by

Charles University in Prague, Center for Economic Research and Graduate Education (CERGE) and

Economics Institute ASCR, v. v. i. (EI)

CERGE-El, Politických vězňŭ 7, 11121 Prague 1, tel.: +420 224005 153, Czech Republic.

Printed by CERGE-EI, Prague

Subscription: CERGE-EI homepage: http://www.cerge-ei.cz

Editors: Directors of CERGE and EI

Managing editors: Deputy Directors for Research of CERGE and EI

ISSN 1211-3298

ISBN 978-80-7343-184-6 (Univerzita Karlova. Centrum pro ekonomický výzkum

a doktorské studium)

ISBN 978-80-7344-173-9 (Národohospodářský ústav AV ČR, v. v. i.) 